\title{
Optical diversity of thaw ponds in discontinuous permafrost: A model system for water color analysis
}

\author{
Shohei Watanabe, ${ }^{1,2}$ Isabelle Laurion, ${ }^{2,3}$ Karem Chokmani, ${ }^{3}$ Reinhard Pienitz, ${ }^{2,4}$ \\ and Warwick F. Vincent ${ }^{1,2}$ \\ Received 4 April 2010; revised 10 January 2011; accepted 24 January 2011; published 15 April 2011.
}

[1] Permafrost thaw ponds result from the irregular melting and erosion of frozen soils, and they are active sites of greenhouse gas emissions to the atmosphere throughout the circumpolar North. In the discontinuous permafrost region of Nunavik, Canada, thaw ponds show pronounced differences in color even among nearby ponds, ranging from white to green, brown and black. To quantify this optical variation and to determine its underlying controlling mechanisms, we studied the apparent and inherent optical properties and limnological characteristics of the ponds. The pond colors were well separated on a color coordinate diagram, with axis values determined from above-water spectral reflectance measurements. Our analyses of optical properties and their empirical relationships with optically active substances showed that the differences in color could entirely be attributed to variations in the concentration of two optically active substances: dissolved organic carbon, which was a major contributor to spectral absorption, and nonalgal suspended particulate matter, which contributed to spectral scattering as well as absorption. The latter component was dominated by small sized particles that had unusually high mass-specific absorption and scattering properties. Analysis of high spatial resolution, multispectral satellite imagery of these ponds showed that these two optically important constituents could be estimated by multivariate modeling. The results indicate that remote sensing surveys will provide valuable synoptic observations of permafrost thaw ponds across the vast subarctic region, and may allow scaling up of local greenhouse gas flux measurements to regional and circumpolar scales.

Citation: Watanabe, S., I. Laurion, K. Chokmani, R. Pienitz, and W. F. Vincent (2011), Optical diversity of thaw ponds in discontinuous permafrost: A model system for water color analysis, J. Geophys. Res., 116, G02003, doi:10.1029/2010JG001380.

\section{Introduction}

[2] Permafrost thaw lakes and ponds (also referred as thermokarst systems) are widespread throughout highlatitude regions, and are formed by the localized melting and erosion of permafrost terrain [Pienitz et al., 2008, and references therein]. These aquatic systems are currently attracting considerable scientific attention related to the impact of climate change. Permafrost soils contain vast amounts of organic carbon [Ping et al., 2008; Tarnocai, 2009; Zimov et al., 2006] and thaw ponds can serve as biogeochemical hot spots of microbial and photochemical

\footnotetext{
${ }^{1}$ Département de Biologie, Université Laval, Quebec City, Quebec, Canada.

${ }^{2}$ Centre d'études nordiques, Université Laval, Quebec City, Quebec, Canada.

${ }^{3}$ Centre Eau Terre Environnement, Institut national de la recherche scientifique, Quebec City, Quebec, Canada.

${ }^{4}$ Département de Géographie, Université Laval, Quebec City, Quebec, Canada.

Copyright 2011 by the American Geophysical Union. 0148-0227/11/2010JG001380
}

degradation, converting permafrost carbon to greenhouse gases $\left(\mathrm{CO}_{2}\right.$ and $\left.\mathrm{CH}_{4}\right)$, which are then released to the atmosphere [Laurion et al., 2010; Walter et al., 2006]. Despite their wide distribution and importance in regional and global biogeochemistry, the limnological characteristics of thaw ponds have been little explored.

[3] The discontinuous permafrost region in Nunavik, Canada, contains numerous thaw ponds (Figure 1). One of their striking features is their variation in color, ranging from white to green, brown, or black, even among adjacent ponds (Figure 2). This pronounced difference in color implies variation in their underwater optical conditions, reflecting the large limnological variability among ponds [Breton et al., 2009]. Additionally, it has been reported that the optical properties of these waters correlate with their rates of greenhouse gas emission [Laurion et al., 2010]. Therefore, detailed information regarding the optical conditions of thaw ponds may provide insights into their limnology as well as the regional biogeochemistry of this high-latitude biome.

[4] Color perceived by the human eye can be numerically described by transposing radiometric measurements onto a 


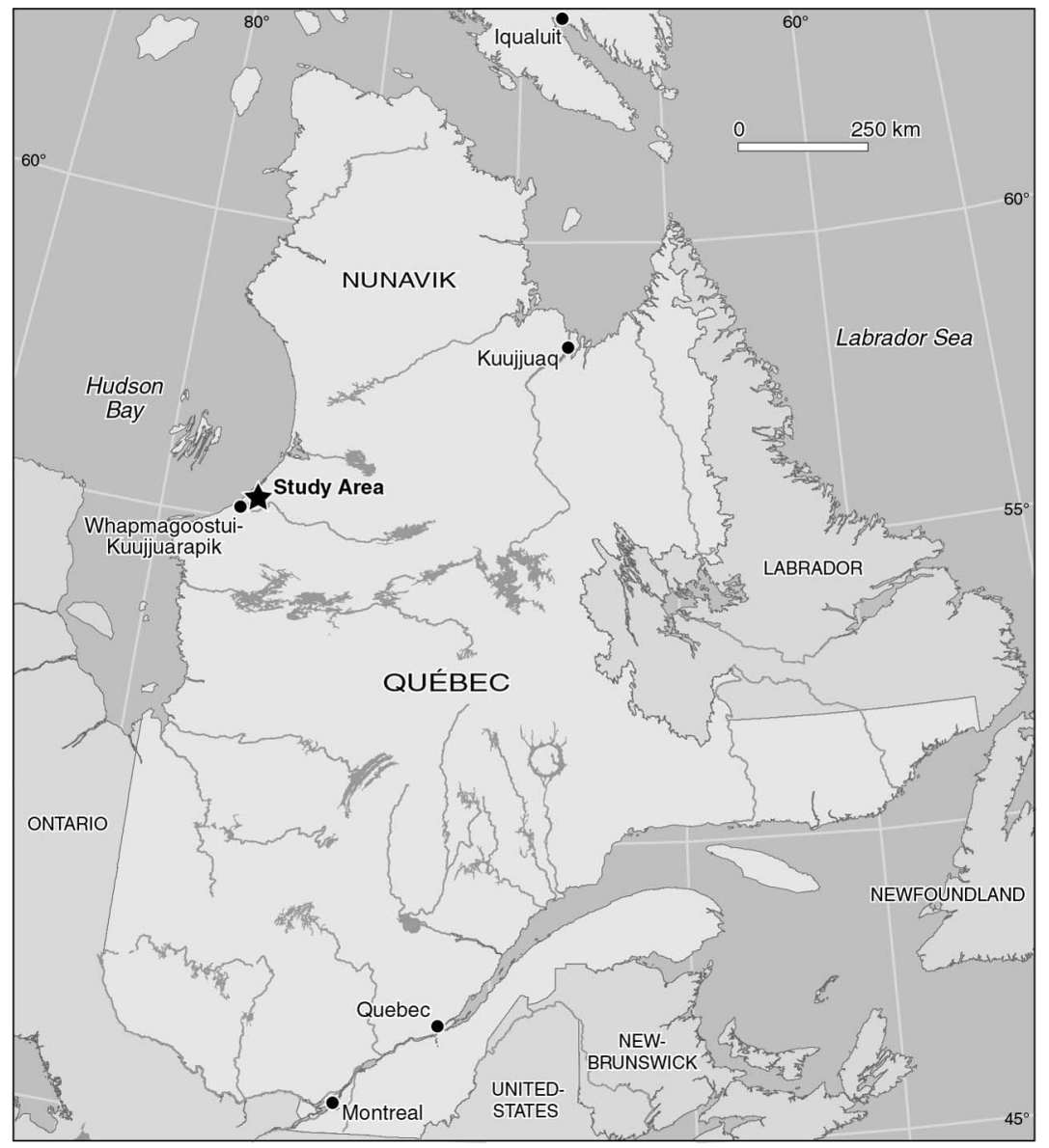

Figure 1. Map of study area. The study sites were located in a discontinuous permafrost region near Whapmagoostui-Kuujjuarapik, Nunavik, Canada $\left(55^{\circ} 20^{\prime} \mathrm{N}, 77^{\circ} 30^{\prime} \mathrm{W}\right)$.

colorimetric coordinate system. Standardized conversion methods have been proposed by the Commission Internationale d'Éclairage (CIE), and these have been widely applied [Schanda, 2007]. For natural waterbodies, measurements of their above-water apparent optical properties (AOP) can be converted into colorimetric coordinate values, which may provide a quantitative means to test the relationship between color and specific limnological variables. This approach offers a potentially useful tool for resource management (e.g., for assessments of aesthetic value and water quality); however, it has been applied to only a limited extent to date [Duntley, 1963; Oyama and Shibahara, 2009; Tyler, 1964].

[5] Optical conditions reflect the biogeochemical characteristics of the waterbody, and can therefore be used to monitor changes in the ecosystem [International OceanColor Coordinating Group (IOCCG), 2000]. The relationships among water column constituents, their inherent optical properties (IOP), and remotely monitored optical properties are well known for open ocean systems, where there is a close correlation with chlorophyll $a$ concentrations (case 1 waters) [Morel, 1988], and the resultant models have been applied to evaluate oceanic biogeochemical processes at the global scale [Arrigo et al., 2008; IOCCG, 1999]. Such relationships are, however, still poorly understood in coastal ocean and inland waterbodies, where optical components such as nonalgal suspended particulate matter, terrigenous dissolved organic matter, and phytoplankton pigments independently vary (case 2 waters), and development of a universally applicable robust model is difficult due to the diversity and complexity of optical conditions [IOCCG, 2000]. Locally adapted models are, however, proving to be increasingly useful tools for coastal and inland water resource management, and have been successfully applied to estimate chlorophyll $a$ [Oyama et al., 2009; Tyler et al., 2006], phycocyanin [Simis et al., 2005], and suspended particulate matter concentrations [Li et al., 2003]. Such models to estimate limnological correlates of $\mathrm{CO}_{2}$ and $\mathrm{CH}_{4}$ concentrations in thaw ponds [Laurion et al., 2010; Sobek et al., 2005] would provide an approach toward the scaling up of greenhouse gas measurements in highlatitude waters to regional and global scales. Additionally, the IOP analysis of diverse thaw ponds provides opportunities to extend existing models, and to expand our knowledge of optical processes in optically complex case 2 waters.

[6] In the present study, our overall objectives were to quantify the range of optical conditions in thaw ponds in the discontinuous permafrost region, and to determine the underlying mechanisms causing their striking differences in color. First, we quantified pond colors from above-water spectral reflectance measurements, and analyzed the influence of limnological conditions on water color. Second, we examined the IOPs of these ponds and evaluated the optical characteristics of optically active substances within the water column. Finally, we made an initial assessment of 


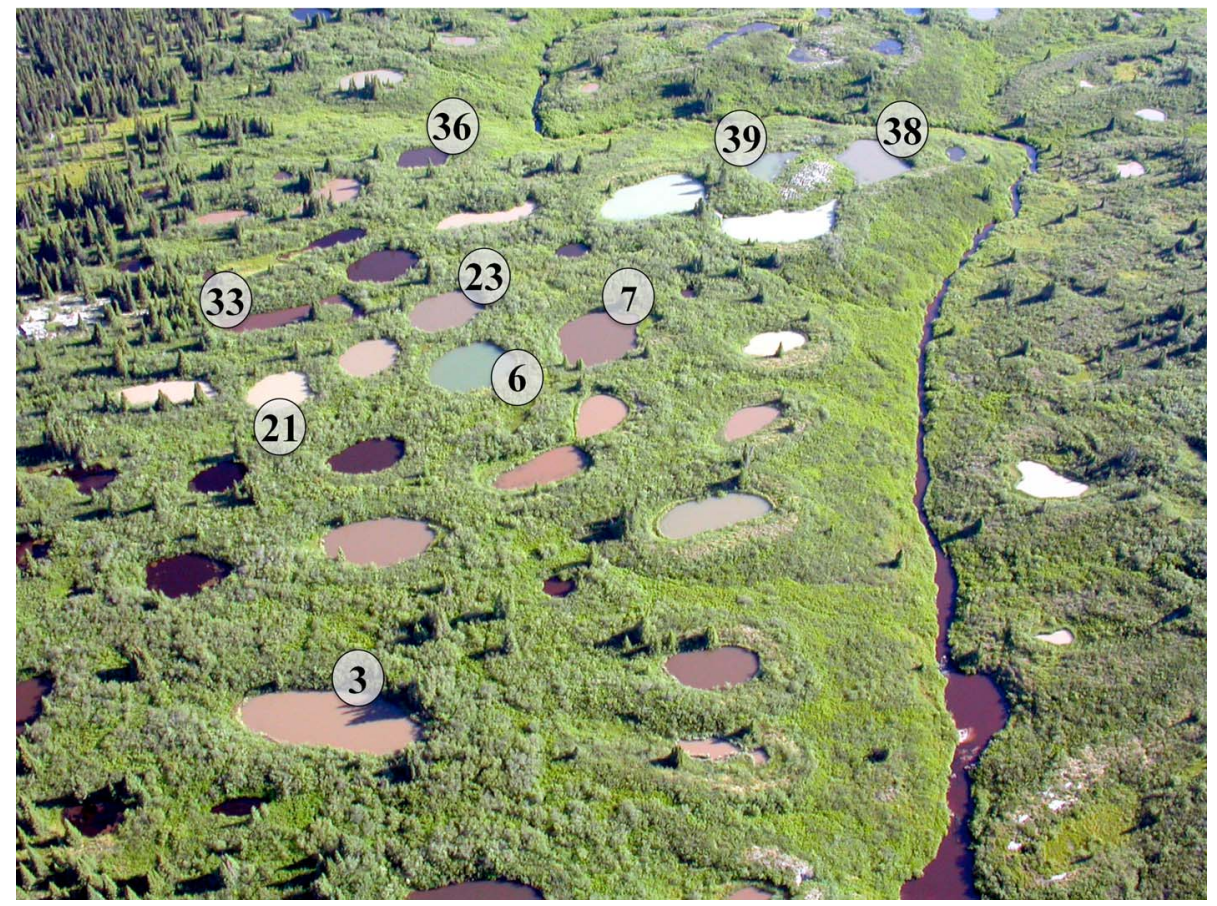

Figure 2. Aerial photograph of the study site, showing some of the sampled thaw ponds (numbers as in the text).

satellite imagery as an approach toward estimating key limnological characteristics of permafrost thaw ponds.

\section{Materials and Methods}

\subsection{Study Site and Field Sampling}

[7] The study site was located in a discontinuous permafrost region near Whapmagoostui-Kuujjuarapik, Nunavik, Canada $\left(55^{\circ} 20^{\prime} \mathrm{N}, 77^{\circ} 30^{\prime} \mathrm{W}\right.$; Figure 1$)$, where there are more than 40 ponds within an area of approximately $0.2 \mathrm{~km}^{2}$ (Figure 2). The ponds were numbered and referred as KWK ponds. At the time of sampling, each pond was $10-30 \mathrm{~m}$ in diameter with a maximum depth of 2-3 m. Detailed limnological information for these waters is given by Breton et al. [2009] and Laurion et al. [2010].

[8] Fourteen ponds representing the full range of limnological conditions [Breton et al., 2009] were sampled between 28 June and 7 July 2007 to characterize AOPs, IOPs, and their controlling factors. Sampling was conducted between 0900 and 1500 local time (EST) at the center of the ponds, which generally corresponded to the deepest point. Surface water samples $(50 \mathrm{~cm}$ below the surface) were taken with Nalgene amber polyethylene bottles and kept refrigerated $\left(4^{\circ} \mathrm{C}\right)$ in the dark until processing within $10 \mathrm{~h}$ of collection.

\subsection{Limnological Variables}

[9] Total phosphorus (TP) was measured by spectrophotometry as described by Stainton et al. [1977]. Water samples were filtered onto Whatman $\mathrm{GF} / \mathrm{F}$ filters and stored frozen $\left(-40^{\circ}\right.$ to $\left.-80^{\circ} \mathrm{C}\right)$ until laboratory analysis for chlorophyll $a(\mathrm{Chl} a)$. Pigments were extracted in ethanol and Chl $a$ concentration was determined by fluorometry (Varian Cary Eclipse spectrofluorometer, Varian Inc., Canada) before and after acidification [Nusch, 1980]. Samples were also filtered onto precombusted, preweighed $\mathrm{GF} / \mathrm{F}$ filters to quantify suspended particulate matter. Filters were weighed after drying for $2 \mathrm{~h}$ at $60^{\circ} \mathrm{C}$ to determine total suspended particulate matter $\left(\mathrm{SPM}_{\mathrm{T}}\right)$. Subsequently, filters were combusted at $500^{\circ} \mathrm{C}$ for $2 \mathrm{~h}$, and then inorganic suspended particulate matter $\left(\mathrm{SPM}_{\mathrm{I}}\right)$ was quantified. Organic suspended particulate matter $\left(\mathrm{SPM}_{\mathrm{O}}\right)$ estimates were obtained as the difference between $\mathrm{SPM}_{\mathrm{T}}$ and $\mathrm{SPM}_{\mathrm{I}}$. Dissolved organic carbon (DOC) concentrations were measured with a Shimadzu TOC-5000A carbon analyzer on filtrates passed through prerinsed cellulose acetate filters (pore size $0.2 \mu \mathrm{m}$, Advantec Micro Filtration Systems Inc., USA).

\subsection{Apparent Optical Properties}

\subsubsection{Within Water AOPs}

[10] Vertical profiles of spectral downwelling irradiance $\left(E_{d}(\lambda), \mu \mathrm{W} \mathrm{cm}{ }^{-2} \mathrm{~nm}^{-1}\right)$ were obtained with a hyperspectral radiometer system (Satlantic Inc., Canada). The instrument was manually lowered at approximately $1 \mathrm{~cm} \mathrm{~s}^{-1}$. Raw radiometer data were processed by ProSoft (Version 7.7.9. Satlantic Inc., Canada) to obtain the spectral profile of $E_{d}(\lambda)$ from 352 to $797 \mathrm{~nm}$ at $1 \mathrm{~nm}$ intervals, and the depth profile at $1 \mathrm{~cm}$ intervals. The vertical profile of photosynthetically active radiation (PAR) of downwelling irradiance $\left(E_{d}(P A R)\right)$ was calculated by integrating $E_{d}(\lambda)$ from 400 to $700 \mathrm{~nm}$. $K_{d}(P A R)$ values, the attenuation coefficients for $E_{d}(P A R)$, were then calculated as the slopes of the linear regression of natural $\log$ transformed $E_{d}(P A R)$ against depth. This calculation was conducted for the depth interval from the surface to the point where $E_{d}(P A R)$ was reduced to $10 \%$ of surface irradiance.

\subsubsection{Above-Water AOPs}

[11] $E_{d}(\lambda)$ and the spectral upwelling radiance $\left(L_{u}(\lambda)\right.$, $\mu \mathrm{W} \mathrm{cm} \mathrm{cm}^{-2} \mathrm{~nm}^{-1} \mathrm{sr}^{-1}$ ) were measured above each waterbody with the hyperspectral radiometer immediately prior to the 
vertical profiling. The instrument was held $10-15 \mathrm{~cm}$ above the surface and data were recorded for $20 \mathrm{~s}$. The variation of measured downwelling irradiance $\left(E_{d}(\lambda)\right)$ was less than $1 \%$ for most observations (maximum $2 \%$ ), and that of upwelling radiance $\left(L_{u}(\lambda)\right)$ was less than $5 \%$. These above-surface measurements were then averaged over the sampling period. To quantify the color of each waterbody, the proportion of surface leaving radiance to incident irradiance (spectral reflectance, $R(\lambda)$ ) was calculated as:

$$
R(\lambda)=\frac{L_{u}(\lambda)}{E_{d}(\lambda) / 2 \pi}
$$

The $E_{d}(\lambda)$ values were divided by $2 \pi$ steradians giving units that were the same for the denominator and numerator ( $\mu \mathrm{W} \mathrm{cm} \mathrm{cm}^{-1} \mathrm{sr}^{-1}$ ), and thereby producing spectra of reflectance in dimensionless units. This ratio differs from the remote sensing reflectance in that the surface leaving radiance acquisition was not conducted at the recommended angle for such a measure and a correction for sky reflection by the sky radiance was not applied [Mobley, 1999; Mueller et al., 2002]. However, two lines of evidence suggest that sky reflection did not have a major effect on the shape of the $R(\lambda)$ spectra. First, in optically shallower ponds where underwater profiles of $L_{u}(\lambda)$ were obtained, the $L_{u}(\lambda)$ spectra for just below the water surface closely matched the above-water $L_{u}(\lambda)$ spectra. Second, our measured $R(\lambda)$ values clearly quantified and separated the differences in pond water color (which would not be the case, if sky reflection dominated the measurements), which thereby allowed a quantitative assessment of the influence of limnological variables on water color.

\subsubsection{CIE $L^{*} a^{*} b^{*}$ Color Coordinates}

[12] We used the CIE $L^{*} a^{*} b^{*}$ color coordinate system, in which axis $L^{*}$ describes lightness in the range from zero to 100 and axis $a^{*}$ expresses the green (negative values) to red (positive values) transition. Similarly, the $b^{*}$ axis describes the blue (negative values) to yellow (positive values) transition [Schanda, 2007]. We adopted this color coordinate system because it had an advantage over other indices, such as the CIE $x y Y$ color space [see Duntley, 1963; Oyama and Shibahara, 2009; Tyler, 1964], in that it includes a component for lightness. This greatly differentiated the waterbodies of the present study.

[13] To convert above-water AOP measurements to CIE $L^{*} a^{*} b^{*}$ coordinates, $R(\lambda)$ was translated into $X, Y$, and $Z$ coordinates that describe the quantitative response of human eyes to red, green, and blue light, respectively, using the following equations:

$$
\begin{aligned}
& X=k \sum_{\lambda=380}^{780} R(\lambda) \cdot S(\lambda) \cdot \bar{x}(\lambda) \Delta \lambda \\
& Y=k \sum_{\lambda=380}^{780} R(\lambda) \cdot S(\lambda) \cdot \bar{y}(\lambda) \Delta \lambda \\
& Z=k \sum_{\lambda=380}^{780} R(\lambda) \cdot S(\lambda) \cdot \bar{z}(\lambda) \Delta \lambda
\end{aligned}
$$

where $S(\lambda)$ is the CIE standard illuminant D65, which represents the radiant power distribution of incident solar radiation giving natural viewing conditions for the ponds $[C I E, 1986] ; \bar{x}(\lambda), \bar{y}(\lambda)$, and $\bar{z}(\lambda)$ are tristimulus constants, which represent wavelength dependent responses of human eyes to red, green, and blue, respectively [CIE, 1931]; and $k$ is a constant to set $Y=100$ for an object whose $R(\lambda)$ is 1 (perfect reflective material), defined as:

$$
k=\frac{100}{\sum_{\lambda=380}^{780} S(\lambda) \cdot \bar{y}(\lambda) \Delta \lambda}
$$

These summations were calculated at $1 \mathrm{~nm}$ intervals. The resultant $X, Y$, and $Z$ coordinates were translated into $L^{*} a^{*} b^{*}$ color space as:

$$
\begin{gathered}
L^{*}=116\left(\frac{Y}{Y_{n}}\right)-16 \\
a^{*}=500\left[\left(\frac{X}{X_{n}}\right)^{\frac{1}{3}}-\left(\frac{Y}{Y_{n}}\right)^{\frac{1}{3}}\right] \\
b^{*}=200\left[\left(\frac{Y}{Y_{n}}\right)^{\frac{1}{3}}-\left(\frac{Z}{Z_{n}}\right)^{\frac{1}{3}}\right]
\end{gathered}
$$

where $X_{n}, Y_{n}$, and $Z_{n}$ are $X, Y$, and $Z$ values of a perfectly reflective material, and defined as:

$$
\begin{aligned}
X_{n} & =k \sum_{\lambda=380}^{780} S(\lambda) \cdot \bar{x}(\lambda) \Delta \lambda \\
Y_{n} & =k \sum_{\lambda=380}^{780} S(\lambda) \cdot \bar{y}(\lambda) \Delta \lambda \\
Z_{n} & =k \sum_{\lambda=380}^{780} S(\lambda) \cdot \bar{z}(\lambda) \Delta \lambda
\end{aligned}
$$

\subsection{Inherent Optical Properties}

\subsubsection{Absorption Coefficient of Colored Dissolved Organic Matter}

[14] Water samples filtered through Whatman GF/F filters were then refiltered through prerinsed cellulose acetate filters (pore size $0.2 \mu \mathrm{m}$ ), and refrigerated in amber glass bottles until colored dissolved organic matter (CDOM) analysis. The absorbance $(A(\lambda))$ of the filtrate against pure water prepared by a Barnstead EASY pure II UV/UF system was measured from 250 to $800 \mathrm{~nm}$ at $1 \mathrm{~nm}$ intervals in a $1 \mathrm{~cm}$ quartz cuvette using a Varian Cary 100 dual beam spectrophotometer (Varian Inc., Canada). The absorption coefficients of $\mathrm{CDOM}\left(a_{C D O M}(\lambda)\right)$ were calculated as:

$$
a_{\text {CDOM }}(\lambda)=\frac{2.303 A(\lambda)}{L}
$$

where $L$ is the path length of the cuvette [Bricaud et al., 1981; Mitchell et al., 2002]. Null point correction was conducted by subtracting the average of $a_{C D O M}(\lambda)$ from 750 to $760 \mathrm{~nm}$ from all spectra. Note that the range used for the correction here is somewhat short and the spectral curves have not yet flattened around this range for these highly colored water samples [Mitchell et al., 2000, 2002]. The null 
point correction at this range was, however, adopted to maintain consistency with other optical measurements, especially with the AC-S (see below). The exponential slope parameters $\left(S_{C D O M}\right)$ of the spectra were calculated by nonlinearly fitting the measured value from 300 to $650 \mathrm{~nm}$ to the equation:

$$
a_{C D O M}(\lambda)=a_{C D O M}\left(\lambda_{0}\right) e^{-S_{C D O M}\left(\lambda-\lambda_{0}\right)}
$$

where $\lambda_{0}$ is the reference wavelength [Bricaud et al., 1981; Stedmon et al., 2000]. $S_{C D O M}$ can be sensitive to the null point correction value (e.g., at $850 \mathrm{~nm}$ ) and the fitted wavelength range (e.g., 305-440 nm [Morris et al., 1995], 375-500 nm [Bricaud et al., 1981]). In our results, differences in $S_{C D O M}$ values among different methods were small. For example, the absorption spectra of KWK 7 showed $S_{C D O M}$ of 0.0146 , 0.0144 , and $0.0144 \mathrm{~nm}^{-1}$ for the fitted range of $305-440 \mathrm{~nm}$, $375-500 \mathrm{~nm}$, and $300-650 \mathrm{~nm}$, respectively, when the spectra were corrected with the null point value as described above. For an alternative null point value at $850 \mathrm{~nm}$, the resultant $S_{C D O M}$ values were $0.0145,0.0141$, and $0.0142 \mathrm{~nm}^{-1}$. The DOC specific absorption of CDOM $\left(a_{C D O M}^{*}(\lambda)\right)$ was calculated as $a_{C D O M}(\lambda)$ divided by DOC concentration.

\subsubsection{Absorption Coefficients of Suspended Particulate Matter}

[15] Suspended particles were collected on Whatman GF/ $\mathrm{F}$ filters and stored at -40 to $-80^{\circ} \mathrm{C}$ until optical analysis. The $A(\lambda)$ of suspended particulate matter was measured by the wet filter technique in the same spectrophotometer as above equipped with an integrating sphere (Labsphere Inc., USA), following Mitchell et al. [2002]. The $A(\lambda)$ of nonalgal particles (NAP) was measured by extracting algal pigments with boiling methanol [Kishino et al., 1985; Mitchell et al., 2002]. The absorption coefficients of suspended particulate matter and $\operatorname{NAP}\left(a_{p}(\lambda)\right.$ and $a_{N A P}(\lambda)$, respectively) were calculated as:

$$
a_{p}(\lambda) \quad \text { or } \quad a_{N A P}(\lambda)=\frac{2.303 A(\lambda) \cdot T}{\beta \cdot V}
$$

where $T$ is the filtered area, $V$ is filtered volume, and $\beta$ is the path length amplification factor [Mitchell et al., 2002]. $\beta=2$ was used after Roesler [1998]. Null point correction was applied in the same manner as above. The absorption of algal particles $\left(a_{\Phi}(\lambda)\right)$ was obtained by subtracting $a_{N A P}(\lambda)$ from $a_{p}(\lambda)$. Similar to $a_{C D O M}(\lambda)$, the exponential slope of $a_{N A P}(\lambda), S_{N A P}$, was calculated by fitting to equation (7). Nonlinear regression was conducted over the spectral range of 380-730 $\mathrm{nm}$ excluding the ranges 400-480 and 620-710 $\mathrm{nm}$ to eliminate the residual pigment absorption [Babin et al., 2003b; Belzile et al., 2004]. The $\mathrm{SPM}_{\mathrm{T}}$ specific absorption of NAP $\left(a_{N A P}^{*}(\lambda)\right)$ and Chl $a$ specific absorption of algal particles $\left(a_{\Phi}^{*}(\lambda)\right)$ were also calculated.

[16] Chemical oxidation by the $\mathrm{NaClO}$ method [Ferrari and Tassan, 1999; Tassan and Ferrari, 1995] was also conducted on separately prepared filters. The results showed noticeably lower $a_{N A P}(\lambda)$ values compared to the results of methanol extraction, and we suspect that $\mathrm{NaClO}$ oxidation changed the optical characteristics of suspended detritus particles. We therefore did not use this method, and suggest that it be used with caution for waterbodies rich in strongly colored organic particles.

\subsubsection{AC-S Measurements}

[17] The absorption and beam attenuation coefficients of water samples excluding those of pure water $\left(a_{t-w}(\lambda)\right.$ and $c_{t-w}(\lambda)$, respectively) were measured using a WET Labs AC-S in situ spectrophotometer $(25 \mathrm{~cm}$ path length, WET Labs Inc., USA) on the laboratory bench. All measurements were completed within $10 \mathrm{~h}$ of sampling, and the instrument configuration and calibration were as described by Sullivan et al. [2006]. Samples were transferred very slowly to the instrument to avoid inclusion of bubbles inside the tubing system, and once the tubes were filled, the spectra were recorded for $20 \mathrm{~s}$. This measurement process was repeated three times for each sample. Each reading was averaged over recorded time, and then all triplicates were averaged to obtain raw readings for each waterbody.

[18] The AC-S readings were calibrated against pure water, and were corrected for temperature and scattering. The pure water calibration values were obtained immediately before the sampling period, and subtracted from the raw readings [Pegau et al., 2003; Twardowski et al., 1999]. The temperature correction was applied by using the spectral correction coefficients obtained specifically for our instrument [Pegau et al., 2003; Sullivan et al., 2006; Twardowski et al., 1999]. The null point correction, subtracting the absorption coefficient at the longest wave band measured by the instrument $(751.7 \mathrm{~nm})$, was adopted as the scattering correction method for our study [Pegau et al., 2003]. Although some authors recommended the proportional correction, which takes into account the wavelength dependency of measurement error of the reflective tube absorption meter [Kirk, 1992; Pegau et al., 2003; Zaneveld et al., 1994], we found that this often yielded lower values compared to absorption measurements obtained by conventional spectrophotometry. The $a_{t-w}(\lambda)$ values were always lower than the sum of $a_{p}(\lambda)$ and $a_{C D O M}(\lambda)$, and often even lower than $a_{C D O M}(\lambda)$, and so this method was not applied. Similarly, an approach suggested by Gallegos and Neale [2002] to obtain scattering correction coefficients did not provide reasonable estimates (the linear equation system gave negative values), and could not be applied in our study. Finally, the absorption coefficients of pure water $\left(a_{w}(\lambda)\right)$ [Pope and Fry, 1997] were added to $a_{t-w}(\lambda)$ to obtain total absorption of the waterbodies $\left(a_{t}(\lambda)\right)$.

[19] The total scattering coefficients by suspended particles $\left(b_{p}(\lambda)\right)$ were obtained by subtracting $a_{t-w}(\lambda)$ from $c_{t-w}(\lambda) . \mathrm{SPM}_{\mathrm{T}}$ specific scattering coefficients $\left(b_{p}^{*}(\lambda)\right)$ were obtained by dividing $b_{p}(\lambda)$ by $\mathrm{SPM}_{\mathrm{T}}$. To characterize the shape of $b_{p}(\lambda)$ spectra, the observations were nonlinearly fitted to the hyperbolic model as:

$$
b_{p}(\lambda)=b_{p}(555) \times\left(\frac{\lambda}{555}\right)^{-n}
$$

where $n$ is the hyperbolic exponent [Babin et al., 2003a; Belzile et al., 2004]. The particle single scattering albedo $\left(\omega_{p}(\lambda)\right)$ was obtained as:

$$
\omega_{p}(\lambda)=\frac{b_{p}(\lambda)}{c_{p}(\lambda)}
$$

where $c_{p}(\lambda)$ is the beam attenuation coefficient by particles that was obtained by subtracting $a_{C D O M}(\lambda)$ from $c_{t-w}(\lambda)$. 


\subsubsection{Absorption Coefficient of Fine Particles}

[20] We found that filtrates of GF/F filters were often visibly turbid as a result of high concentrations of fine particles, and these particles were removed by subsequent filtration using the cellulose acetate filters. There were also significant differences between $a_{t-w}(\lambda)$ obtained with the $\mathrm{AC}-\mathrm{S}$ and the sum of $a_{p}(\lambda)$ plus $a_{C D O M}(\lambda)$. This difference was defined as the absorption coefficient of fine particles $\left(a_{\text {fine }}(\lambda)\right)$ in this study.

\subsubsection{Validation of AC-S Related Measurements}

[21] The initial value of both the absorption and attenuation measurements made by the AC-S often exceeded the instrumental upper detection limit $\left(10 \mathrm{~m}^{-1}\right)$. Therefore, samples were diluted by measured volumes of pure water until the values reached less than $10 \mathrm{~m}^{-1}$ (dilution factor of $2-7$ ). Even though dilution was the only feasible solution to measure samples from extremely colored and turbid systems by the instrument, the process might affect the water optical characteristics, for example by the flocculation of particles and precipitation of dissolved matter. The effect of dilution was, therefore, tested by two different approaches.

[22] First, we compared measured values of diluted and undiluted samples at a longer wavelength $\left(a_{t-w}(604.1)\right.$ and $\left.c_{t-w}(604)\right)$, where observed raw values were always below the detection limit for $a_{t-w}(604.1)$ (four highly turbid samples showed $c_{t-w}(604)>10 \mathrm{~m}^{-1}$ even at this wavelength). The average of the absolute difference between two measurements was $0.13 \mathrm{~m}^{-1}(5.9 \%)$ and $0.13 \mathrm{~m}^{-1}(3.3 \%)$ for absorption $(n=14)$ and attenuation $(n=10)$, respectively. Second, we compared absorption measurements obtained by the two different photometric methods. Surface water was sampled in four ponds (KWK 6, 16, 23, 38) in July 2008. The $a_{t-w}(\lambda)$ was determined by the AC-S with dilutions of one to six, and $a_{C D O M}(\lambda)$ and $a_{p}(\lambda)$ were measured by the laboratory bench top spectrophotometer as described above. In addition, filtrate from $\mathrm{GF} / \mathrm{F}$ filters was refiltered through cellulose acetate filters and the absorption coefficient of materials collected on the filters was determined using the same method as for normal particulate absorption analysis (i.e., $a_{p}(\lambda)$ quantification), as described above [Ferrari and Tassan, 1996; Gallegos, 2005]. Then $a_{t-w}(\lambda)$ and the sum of all bench top spectrophotometer measurements were compared. The obtained spectra showed close correspondence with respect to their shape (Figure S1a, available as auxiliary material). ${ }^{1}$ The average of the absolute difference at $440 \mathrm{~nm}$ was $0.52 \mathrm{~m}^{-1}(6.7 \%)$. These two sets of tests indicated that the effect of dilution on the measurement by AC-S was minimal within the present study.

[23] The measurement of $a_{\text {fine }}(\lambda)$ was also validated with data obtained in four ponds sampled in 2008. We compared $a_{\text {fine }}(\lambda)$ determined as the difference between $a_{t-w}(\lambda)$ and the sum of $a_{p}(\lambda)$ plus $a_{C D O M}(\lambda)$ with the absorption coefficients of materials collected on the $0.2 \mu \mathrm{m}$ cellulose acetate filters measured as above. The absolute difference was $0.52 \mathrm{~m}^{-1}$ $(41.6 \%)$ on average, and the spectra showed differences in shape especially at shorter wavelengths of samples with low to medium concentrations of fine particles (Figure S1b).

${ }^{1}$ Auxiliary materials are available in the HTML. doi:10.1029/ 2010JG001380.
This difference resulted from two intrinsically different spectrophotometer designs. For the AC-S measurement, the error may be exacerbated by the spectral dependency of scattering and its influence on reflective tube absorption measurements [Kirk, 1992; Zaneveld et al., 1994]. Our measurements of $a_{\text {fine }}(\lambda)$ therefore cannot be considered precise estimate of spectral absorption by fine particles. However, differences between $a_{t-w}(\lambda)$ and the sum of $a_{C D O M}(\lambda)$ and $a_{p}(\lambda)$ provided an index of site-to-site variability in the contribution of fine particles to total absorption.

\subsection{Remote Sensing Analysis}

[24] A remote sensing algorithm was developed and evaluated for these thaw ponds using limnological data and satellite imagery obtained in July 2006. Thirty-four ponds were sampled, and $\mathrm{SPM}_{\mathrm{T}}$ and DOC were measured with the same methods as described above. We used a high spatial resolution multispectral image acquired by QuickBird (DigitalGlobe Co., USA) during clear-sky conditions on 7 July 2006. The satellite provides four spectral bands: blue $(450-520 \mathrm{~nm})$, green $(520-600 \mathrm{~nm})$, red $(630-690 \mathrm{~nm})$, and IR (760-900 nm). An atmospheric correction was conducted with Geomatica ${ }^{\circledR}$ (PCI Geomatics, Canada), using the ATCOR2 module for standard subarctic summer atmospheric conditions. Reflectance of each pond was obtained as an average of pixels over the water and excluding those overlapping the adjacent land. (14-105 pixels depending on pond size, where each pixel was $2.4 \times 2.4 \mathrm{~m})$. It is possible that there was some adjacency effect; however, visual inspection of the satellite image indicated that this effect was minor because there was no obvious gradient in color of pixels toward the center of each pond. Bottom effects can also be a problem for satellite remote sensing of shallow waterbodies; however, this was negligible in the present study because all of the ponds were optically deep, with sufficiently high dissolved color and suspended particles to obscure the bottom. For modeling and validation, sampled ponds were randomly separated into calibration $(\mathrm{n}=24)$ and validation $(\mathrm{n}=10)$ data sets.

[25] Color inversion for water quality estimation of case 2 inland waters is relatively difficult compared to that of oceanic case 1 waters due to the complexity of optical processes in the water column $[I O C C G, 2000]$. To overcome this difficulty, various attempts have been made to apply multivariate statistical analyses instead of simple or multiple linear regressions [e.g., Flink et al., 2001; Svab et al., 2005]. We adopted the approach of canonical correlation analysis (CCA), a multivariate statistical technique that examines interrelationships between two sets of variables (multiple Ys against multiple Xs) [Johnson and Wichern, 2007]. It also can be conducted on variable sets with one $Y$ against multiple Xs, providing coefficients for Xs to align with variation of $Y$. The latter method of CCA has been successfully applied to multispectral satellite data for terrestrial systems [e.g., Cohen et al., 2003; Heiskanen, 2006]. We applied this type of CCA to limnological variables $(\mathrm{Y}=$ $\mathrm{SPM}_{\mathrm{T}}$ or DOC) against four reflectance bands of QuickBird data (Xs). The relationships between the limnological variables and the obtained canonical scores were linearly fitted. The performance of the developed models was then evaluated using the validation data set. 
Table 1. Limnological Variables for the 14 Permafrost Thaw Ponds $^{\mathrm{a}}$

\begin{tabular}{lcccc}
\hline Variables & Units & Range & Mean & CV (\%) \\
\hline $\mathrm{Chl}^{\mathrm{b}}$ & $\mu \mathrm{g} \mathrm{L}^{-1}$ & $1.4-23.8$ & 6.2 & 100 \\
$\mathrm{DOC}^{\mathrm{b}}$ & $\mathrm{mg} \mathrm{L}^{-1}$ & $3.1-10.5$ & 7.7 & 27 \\
$\mathrm{SPM}_{\mathrm{T}}$ & $\mathrm{mg} \mathrm{L}^{-1}$ & $5.0-42.4$ & 16.8 & 74 \\
$\mathrm{SPM}_{\mathrm{I}}$ & $\mathrm{mg} \mathrm{L}^{-1}$ & $2.1-36.7$ & 13.0 & 88 \\
$\mathrm{SPM}_{\mathrm{O}}$ & $\mathrm{mg} \mathrm{L}^{-1}$ & $1.6-7.1$ & 3.8 & 47 \\
$\mathrm{TP}^{\mathrm{b}}$ & $\mu \mathrm{g} \mathrm{L}^{-1}$ & $33.6-108.9$ & 60.4 & 41 \\
\hline
\end{tabular}

${ }^{\mathrm{a}} \mathrm{Chl} a$, chlorophyll $a$; DOC, dissolved organic carbon; $\mathrm{SPM}_{\mathrm{T}}$, total suspended particulate matter; $\mathrm{SPM}_{\mathrm{I}}$, inorganic suspended particulate matter; $\mathrm{SPM}_{\mathrm{O}}$, organic suspended particulate matter; TP, total phosphorus.

${ }^{b}$ Data from KWK 16 and 39 were missing $(n=12)$.

\subsection{Statistical Analyses}

[26] All statistical analyses were conducted using the $\mathrm{R}$ language and environment for statistical computing [R Development Core Team, 2009]. Statistical significance was tested at the usual $p=0.05$ level, and exact $p$ values are given for probabilities above 0.01 . Pearson's product moment correlation coefficients ( $r$ ) are given where the significance of correlation between two variables was tested. In turn, $r$ squared $\left(r^{2}\right)$ values are given for linear regression models, along with the associated regression coefficients (slope and intercept) to quantify the relation- ship between optical properties and optically active variables of target waterbodies.

\section{Results}

\subsection{Ambient Conditions}

[27] The thaw ponds in this region encompass a broad range of colors: green, black, brown, and white (Figure 2). Most were thermally stratified with a thermocline at around $1 \mathrm{~m}$ depth. The mean surface temperature was $13.7^{\circ} \mathrm{C}$ (range: $10.4^{\circ}-18.6^{\circ} \mathrm{C}, \mathrm{n}=13$ ) at the time of sampling. $\mathrm{TP}$ varied from 33.6 to $108.9 \mu \mathrm{g} \mathrm{L}^{-1}$ with a mean of $60.4 \mu \mathrm{g} \mathrm{L}^{-1}$ (Table 1). DOC ranged from 3.1 to $10.5 \mathrm{mg} \mathrm{L}^{-1}$ with a mean of $7.7 \mathrm{mg} \mathrm{L}^{-1}$. The mean value of Chl $a$ was $6.2 \mu \mathrm{g} \mathrm{L}^{-1}$. One site (KWK 11) showed exceptionally high $\mathrm{Chl} a$ $\left(23.8 \mu \mathrm{g} \mathrm{L}^{-1}\right)$, but the rest of the observations fell within the range 1.4 to $10.3 \mu \mathrm{g} \mathrm{L}^{-1}$. There were large variations in suspended particulate matter concentrations: $\mathrm{SPM}_{\mathrm{T}}$ ranged from 5.0 to $42.4 \mathrm{mg} \mathrm{L}^{-1}$ (mean: $16.8 \mathrm{mg} \mathrm{L}^{-1}$ ), $\mathrm{SPM}_{\mathrm{I}}$ from 2.1 to $36.7 \mathrm{mg} \mathrm{L}^{-1}$ (mean: $13.0 \mathrm{mg} \mathrm{L}{ }^{-1}$ ), and $\mathrm{SPM}_{\mathrm{O}}$ from 1.6 to $7.1 \mathrm{mg} \mathrm{L}^{-1}$ (mean: $3.8 \mathrm{mg} \mathrm{L}^{-1}$ ). The relationship between $\mathrm{SPM}_{\mathrm{I}}$ and $\mathrm{SPM}_{\mathrm{O}}$ was significant $(\mathrm{r}=$ $0.55, \mathrm{p}=0.04)$. These variables showed much stronger relationships when the outlier with exceptionally high Chl $a(\mathrm{KWK} 11)$ was removed $(\mathrm{r}=0.87, \mathrm{p}<0.01)$. The mean of $\% \mathrm{SPM}_{\mathrm{I}}$ contribution to $\mathrm{SPM}_{\mathrm{T}}$ was $71 \%$ with a
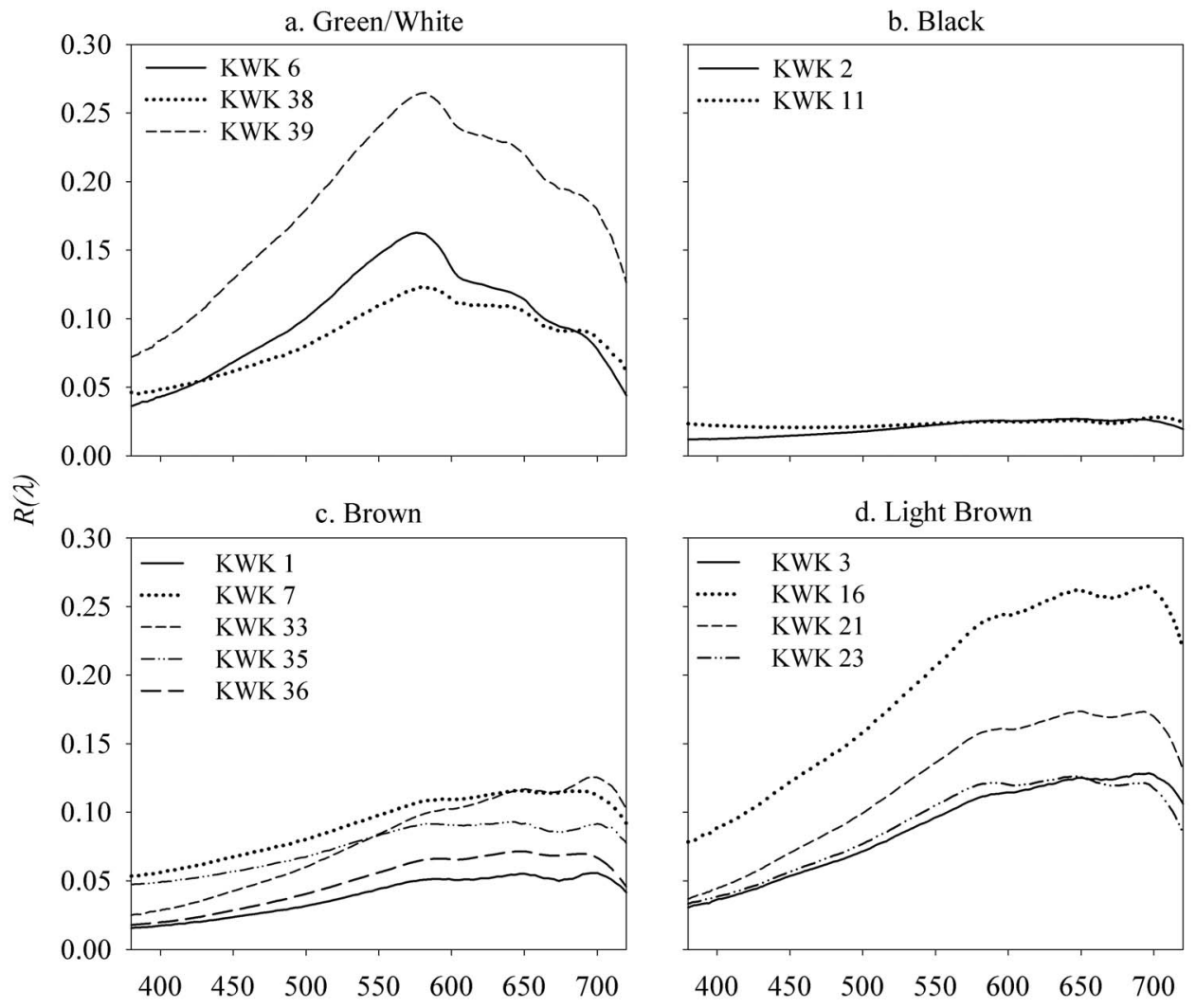

Wavelength $(\mathrm{nm})$

Figure 3. Dimensionless ratio of above-surface upwelling radiance to $2 \pi$ corrected downwelling irradiance $(R(\lambda))$ of studied ponds. Ponds were grouped by visual appearance of color determined on sight and by aerial photographs: (a) green to white, (b) black, (c) brown, and (d) light brown. 


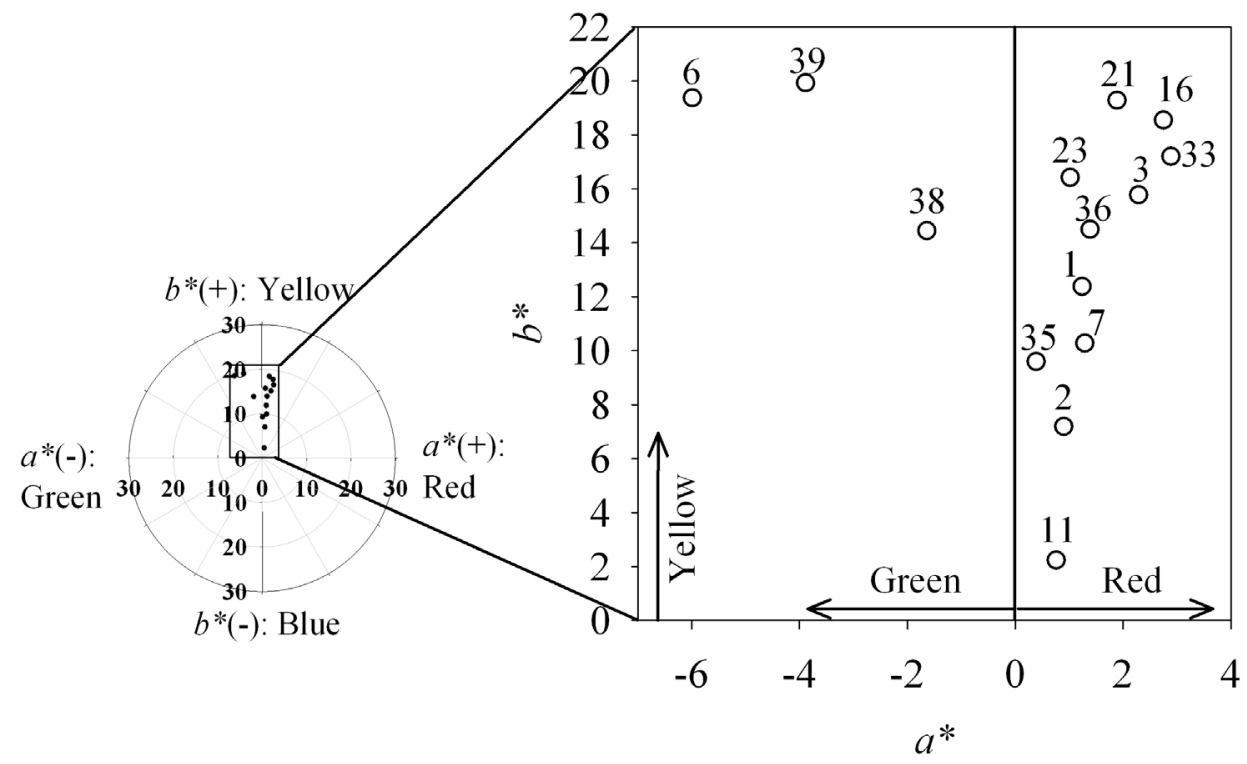

Figure 4. Color of studied ponds expressed in CIE $L^{*} a^{*} b^{*}$ color coordinates. The $a^{*}$ axis shows green to red transition, with negative value indicating greenness and positive value indicating redness. Similarly, the $b^{*}$ axis shows blue to yellow transition, with negative value indicating blueness, and positive value indicating yellowness. The $L^{*}$ axis, indicating lightness, is not shown on the plot (mean of 36.0 with range from 16.8 to 55.0 ).

coefficient of variation (CV) of $26 \%$. Chl $a$ did not correlate with $\mathrm{SPM}_{\mathrm{T}}(\mathrm{r}=0.04, \mathrm{p}=0.89)$, but did correlate with $\mathrm{SPM}_{\mathrm{O}}(\mathrm{r}=0.75, \mathrm{p}<0.01)$; however, the relationship was weaker without KWK $11(\mathrm{r}=0.60, \mathrm{p}=0.05)$.

\subsection{Apparent Optical Properties}

[28] $K_{d}(P A R)$ ranged from 1.70 to $7.50 \mathrm{~m}^{-1}$ with a mean of $3.94 \mathrm{~m}^{-1}$. Among the observed limnological variables, $K_{d}(P A R)$ was strongly correlated with $\operatorname{SPM}_{\mathrm{T}}(\mathrm{r}=0.90, \mathrm{p}<$ $0.01)$ and moderately with DOC $(\mathrm{r}=0.62, \mathrm{p}=0.03)$, but not with Chl $a(\mathrm{r}=0.18, \mathrm{p}=0.58)$. Forward stepwise regression analysis of these data selected $\mathrm{SPM}_{\mathrm{T}}$ and DOC as explanatory variables: $K_{d}(P A R)=0.11 \mathrm{SPM}_{\mathrm{T}}+0.25 \mathrm{DOC}\left(\mathrm{r}^{2}=\right.$ 0.89 ; both $\mathrm{SPM}_{\mathrm{T}}$ and DOC were significant at $\mathrm{p}=0.05$, and the intercept was not significantly different from zero).

[29] The $R(\lambda)$ spectra showed large variations in shape that clustered according to the visual appearance of the ponds (Figures 3a-3d). Green (KWK 6; see Figure 2) or white (KWK 38 and 39) ponds showed relatively high $R(\lambda)$ that peaked around $550 \mathrm{~nm}$ (Figure 3a). Black ponds (KWK 2 and 11) showed low $R(\lambda)$ curves with flat spectra (Figure $3 \mathrm{~b}$ ). Brown ponds showed intermediate levels of $R$ $(\lambda)$ peaking around the orange to red part of the spectrum (Figure 3c). Light brown ponds had high levels of $R(\lambda)$ peaking around 650-700 $\mathrm{nm}$ (Figure 3d).

[30] The CIE $L^{*} a^{*} b^{*}$ color coordinate values, converted from $R(\lambda)$ spectra, well described and separated the pond colors (Figure 4). Three ponds that had green to white color were plotted in the green-yellow quadrant (negative $a^{*}$ and positive $b^{*}$ ) with relatively high $b^{*}$ values, and rest of ponds clustered in the red-yellow quadrant (positive both in $a^{*}$ and $\left.b^{*}\right)$. Among the latter ponds, two black ones showed low $b^{*}$ values. Pond KWK 11 had especially low values in both $a^{*}$ and $b^{*}$. The majority of brown ponds, except for KWK 33, showed intermediate $b^{*}$ values, while the light brown ponds had high $b^{*}$ values.

[31] The $a^{*}$ axis values were strongly correlated with DOC $(\mathrm{r}=0.73, \mathrm{p}<0.01)$, but not with $\operatorname{SPM}_{\mathrm{T}}(\mathrm{r}=0.48, \mathrm{p}=$ $0.08)$, Chl $a(\mathrm{r}=0.21, \mathrm{p}=0.51)$, or the $\mathrm{DOC}: \mathrm{SPM}_{\mathrm{T}}$ ratio $(\mathrm{r}=$ $-0.11, \mathrm{p}=0.73)$. In turn, $b^{*}$ showed a significant negative correlation with the DOC:SPM $\mathrm{T}$ ratio $(\mathrm{r}=-0.70, \mathrm{p}=0.01)$, but not with DOC $(\mathrm{r}=-0.35, \mathrm{p}=0.27)$ or $\mathrm{SPM}_{\mathrm{T}}(\mathrm{r}=0.46$, $\mathrm{p}=0.10)$. The correlation between $b^{*}$ and Chl $a$ was statistically significant $(\mathrm{r}=-0.61, \mathrm{p}=0.04)$; however, this result was largely driven by an outlier that showed exceptionally high Chl $a$ and low $b^{*}$ (KWK 11). Without the outlier, the relationship was not significant $(\mathrm{r}=-0.03, \mathrm{p}=$ $0.92)$. The lightness index $\left(L^{*}\right)$ ranged from 16.8 to 55.0 with a mean of 36.0 , and was significantly correlated with $b^{*}(\mathrm{r}=0.84, \mathrm{p}<0.01)$. This index was correlated negatively with the DOC: $\mathrm{SPM}_{\mathrm{T}}$ ratio $(\mathrm{r}=-0.57, \mathrm{p}=0.05)$, but not with $\operatorname{DOC}(\mathrm{r}=-0.14, \mathrm{p}=0.66), \mathrm{SPM}_{\mathrm{T}}(\mathrm{r}=0.49, \mathrm{p}=0.07)$ or Chl $a(\mathrm{r}=-0.54, \mathrm{p}=0.07)$.

\subsection{Inherent Optical Properties}

\subsubsection{Absorption Coefficient of Colored Dissolved Organic Matter}

[32] $a_{C D O M}(\lambda)$ spectra showed wide variations among ponds (Figure 5a). The absorption coefficient at $440 \mathrm{~nm}$ $\left(a_{C D O M}(440)\right)$ ranged from 1.654 to $9.333 \mathrm{~m}^{-1}$ (mean: $5.461 \mathrm{~m}^{-1}$; Table 2$)$. In contrast, $S_{C D O M}$ varied over a narrow range, from 0.0144 to $0.0159 \mathrm{~nm}^{-1}$ (mean: $0.0150 \mathrm{~nm}^{-1}$ ). The mean value of $a_{C D O M}^{*}(440)$ was $0.743 \mathrm{~m}^{2} \mathrm{~g}^{-1}(0.491-$ $\left.0.962 \mathrm{~m}^{2} \mathrm{~g}^{-1}\right)$. The $a_{C D O M}(440)$ values and DOC were strongly correlated $(\mathrm{r}=0.82, \mathrm{p}<0.01$; Figure 6 , circles $)$. The relationship was similar to that for the data collected in 2006 by Breton et al. [2009] ( $\mathrm{n}=36, \mathrm{r}=0.85, \mathrm{p}<0.01$; Figure 6, triangles). Regression analyses were conducted 

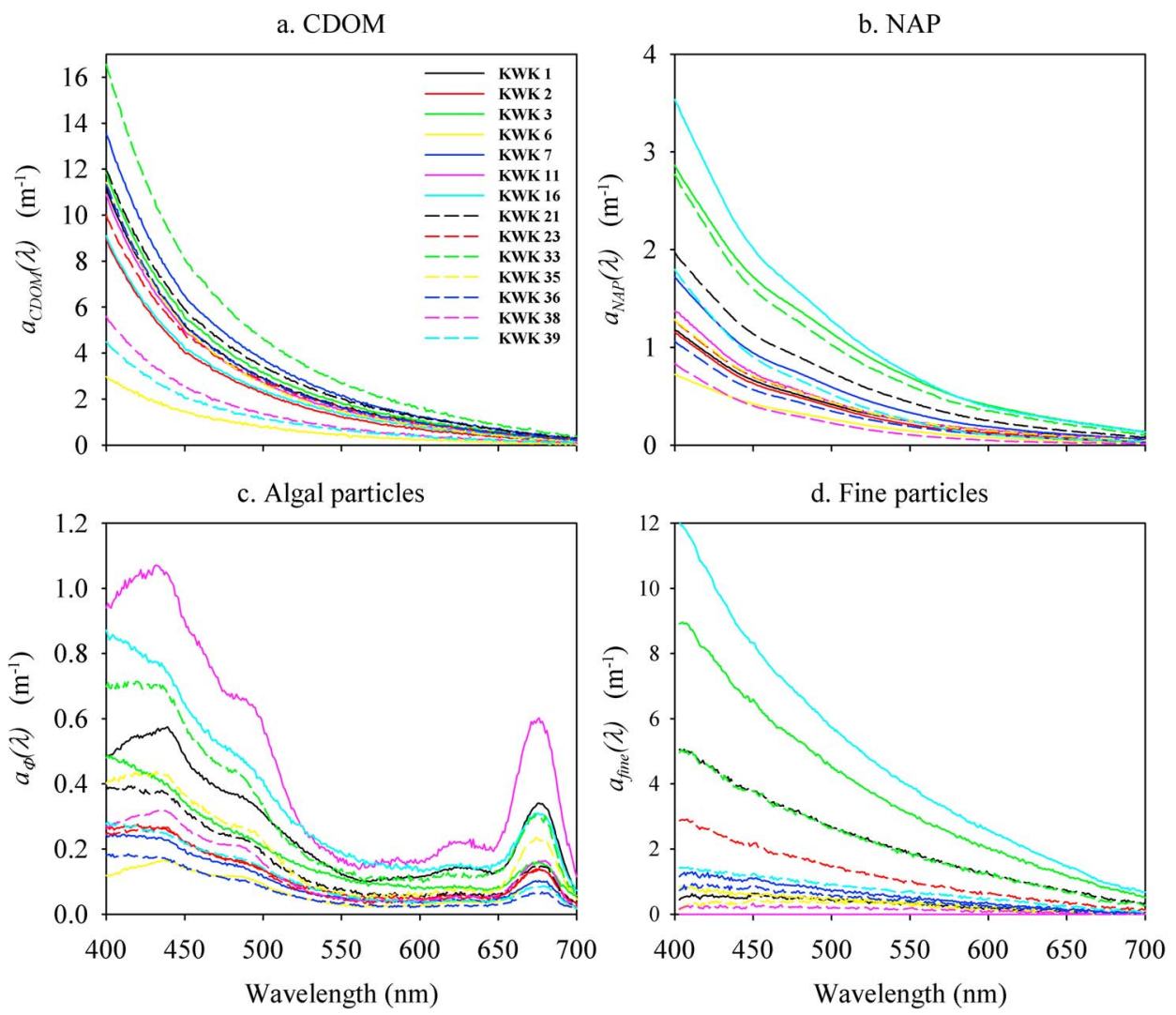

Figure 5. The absorption coefficient spectra from 400 to $700 \mathrm{~nm}$ of (a) colored dissolved organic matter $\left(a_{C D O M}(\lambda)\right)$, (b) nonalgal particles $\left(a_{N A P}(\lambda)\right)$, (c) algal particles $\left(a_{\Phi}(\lambda)\right)$, and (d) fine particles $\left(a_{\text {fine }}(\lambda)\right)$.

on the pooled data $(n=48)$. Both linear and power models were highly significant and indicators of goodness of fit were similar between the two models. The linear model was $a_{\text {CDOM }}(440)=0.742$ DOC $\left(\mathrm{r}^{2}=0.65, \mathrm{p}<0.01\right.$, Akaike's

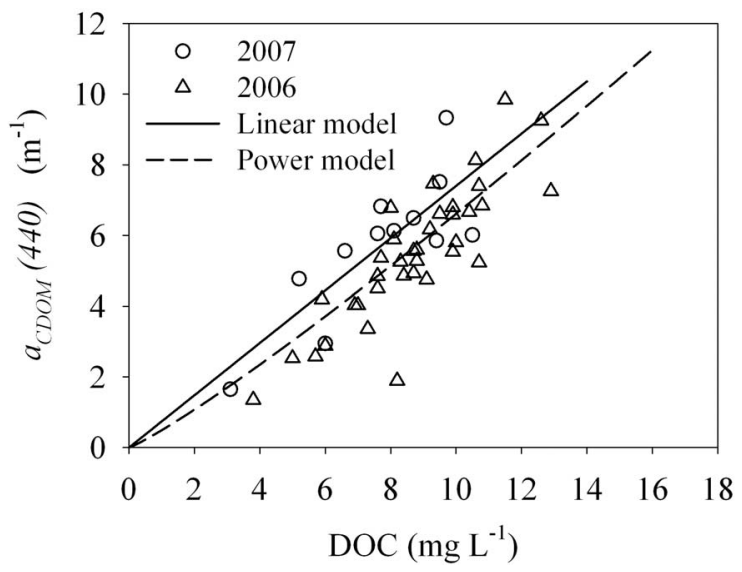

Figure 6. Relationship between absorption coefficient by colored dissolved organic matter at $440 \mathrm{~nm}\left(a_{C D O M}(440)\right)$ and dissolved organic carbon (DOC). Open circles represent data collected in $2007(\mathrm{n}=12)$, and triangles represent data collected in $2006(\mathrm{n}=36)$. The solid line represents the linear model, and the dashed line represents the power model on pooled data $(n=48)$. information criteria $(\mathrm{AIC})=153.7$, regression mean square error $(\mathrm{RMSE})=1.15$, intercept not significantly different from zero), and the power model was $a_{C D O M}(440)=0.495$ $\operatorname{DOC}^{1.129}(\mathrm{p}<0.01$, AIC $=154.0$, RMSE $=1.16)$.

\subsubsection{Absorption Coefficient of Nonalgal Particles}

[33] $a_{N A P}(\lambda)$ spectra also showed a wide variation among the studied ponds (Figure $5 \mathrm{~b}$ and Table 2). $a_{N A P}(440)$ values ranged from 0.464 to $2.240 \mathrm{~m}^{-1}$ with a mean of $1.049 \mathrm{~m}^{-1}$. In contrast, the $S_{N A P}$ varied little (range: $0.0096-$ $\left.0.0136 \mathrm{~nm}^{-1}\right)$ and most of ponds $(\mathrm{n}=10)$ had values $\pm 0.0006 \mathrm{~nm}^{-1}$ from the mean $\left(0.0111 \mathrm{~nm}^{-1}\right) . a_{N A P}^{*}(440)$ varied threefold (Table 2), with the majority of values in the range 0.060 to $0.093 \mathrm{~m}^{2} \mathrm{~g}^{-1}$. The $a_{N A P}(440)$ values showed a strong linear relationship with $\mathrm{SPM}_{\mathrm{T}}: a_{N A P}(440)=0.042$ $\mathrm{SPM}_{\mathrm{T}}+0.342\left(\mathrm{r}^{2}=0.90, \mathrm{p}<0.01 ;\right.$ Figure 7).

\subsubsection{Absorption Coefficient of Algal Particles}

[34] Spectral $a_{\Phi}(\lambda)$ consistently showed a bimodal distribution with some variation in shape (Figure $5 \mathrm{c}$ ). There was a sixfold variation in $a_{\Phi}(440)$ with a mean of $0.415 \mathrm{~m}^{-1}$ (CV: $61 \%$; Table 2), and 10 of the 14 observations were below $0.5 \mathrm{~m}^{-1}$. The range of $a(440)$ was 0.044 to $0.164 \mathrm{~m}^{2} \mathrm{mg}^{-1}$ (mean: $0.086 \mathrm{~m}^{2} \mathrm{mg}^{-1}, \mathrm{CV}$ : 47\%). The $a_{\Phi}(440)$ values and $\mathrm{Chl} a$ were strongly related (Figure 8). Both linear and power models were significant and the goodness of fit was similar for the two models: $a_{\Phi}(440)=0.038 \mathrm{Chl}$ $a+0.167\left(\mathrm{r}^{2}=0.87, \mathrm{p}<0.01\right.$, AIC $=-18.39$, RMSE $=$ $0.096) ; a_{\Phi}(440)=0.136 \mathrm{Chl} a^{0.636}(\mathrm{p}<0.01, \mathrm{AIC}=-18.40$, RMSE $=0.096)$. 
Table 2. Summary of the Absorption Coefficients (a), Specific Absorption Coefficients $\left(a^{*}\right)$, and Exponential Slope Parameters $(S)$ for Optically Active Components in 14 Thaw Ponds ${ }^{\mathrm{a}}$

\begin{tabular}{|c|c|c|c|c|c|}
\hline & Optical Variable & Units & Range & Mean & $\mathrm{CV}$ \\
\hline \multirow[t]{4}{*}{ CDOM } & $a_{\text {СDOM }}(320)$ & $\mathrm{m}^{-1}$ & $9.882-56.047$ & 34.780 & 36 \\
\hline & $a_{C D O M}(440)$ & $\mathrm{m}^{-1}$ & $1.654-9.333$ & 5.461 & 37 \\
\hline & $a_{C D O M}^{*}(440)^{\mathrm{b}}$ & $\mathrm{m}^{2} \mathrm{~g}^{-1}$ & $0.491-0.962$ & 0.743 & 21 \\
\hline & $S_{C D O M}$ & $\mathrm{~nm}^{-1}$ & $0.0144-0.0159$ & 0.0150 & 3 \\
\hline \multirow[t]{3}{*}{ NAP } & $a_{N A P}(440)$ & $\mathrm{m}^{-1}$ & $0.464-2.240$ & 1.049 & 53 \\
\hline & $a_{N A P}^{*}(440)$ & $\mathrm{m}^{2} \mathrm{~g}^{-1}$ & $0.045-0.141$ & 0.073 & 34 \\
\hline & $S_{N A P}$ & $\mathrm{~nm}^{-1}$ & $0.0096-0.0136$ & 0.0111 & 10 \\
\hline \multirow[t]{2}{*}{ Algal particles } & $a_{\Phi}(440)$ & $\mathrm{m}^{-1}$ & $0.162-1.037$ & 0.415 & 61 \\
\hline & $a_{\Phi}^{*}(440)^{\mathrm{b}}$ & $\mathrm{m}^{2} \mathrm{mg}^{-1}$ & $0.044-0.164$ & 0.086 & 47 \\
\hline Fine particles & $a_{\text {fine }}(440)$ & $\mathrm{m}^{-1}$ & $0-8.865$ & 2.180 & 127 \\
\hline Total & $a_{t}(440)$ & $\mathrm{m}^{-1}$ & $2.922-16.773$ & 9.080 & 49 \\
\hline
\end{tabular}

${ }^{\mathrm{a}} \mathrm{CDOM}$, colored dissolved organic matter; NAP, nonalgal particles.

${ }^{\mathrm{b}}$ Data from KWK 16 and 39 were missing $(\mathrm{n}=12)$.

\subsubsection{Absorption Coefficient of Fine Particles}

[35] $a_{\text {fine }}(\lambda)$ showed the greatest variation of any of the component spectra (Figure 5d). The value of $a_{\text {fine }}(440)$ ranged from zero to $8.865 \mathrm{~m}^{-1}$ (mean: $2.180 \mathrm{~m}^{-1}, \mathrm{CV}$ : $127 \%$; Table 2). The correlation analysis showed that this variable had a strong significant correlation with $\mathrm{SPM}_{\mathrm{T}}$ $(\mathrm{r}=0.97, \mathrm{p}<0.01)$ and $a_{N A P}(440)(\mathrm{r}=0.93, \mathrm{p}<0.01)$, although these variables were obtained on $\mathrm{GF} / \mathrm{F}$ filters which did not retain the fine particles.

\subsubsection{Total Absorption}

[36] There was a more than fivefold variation in $a_{t}(440)$ (Figure 9 and Table 2), and the contribution of each absorbing component to the total absorption was also variable among ponds (Table 3). On average, CDOM accounted for more than half of the absorption at $440 \mathrm{~nm}$, but varied from 29 to $85 \%$. The mean NAP contribution to total absorption at $440 \mathrm{~nm}$ was $12 \%$ with little variation (CV: $25 \%$ ). Algal particles were always a minor constituent, ranging from 2 to $14 \%$ with a mean of $5 \%$. The contribution of fine particles varied between 0 and $53 \%$ with a mean of $19 \%$. For half the ponds, fine particles accounted for more than $20 \%$ of total absorption. Multiple linear regres-

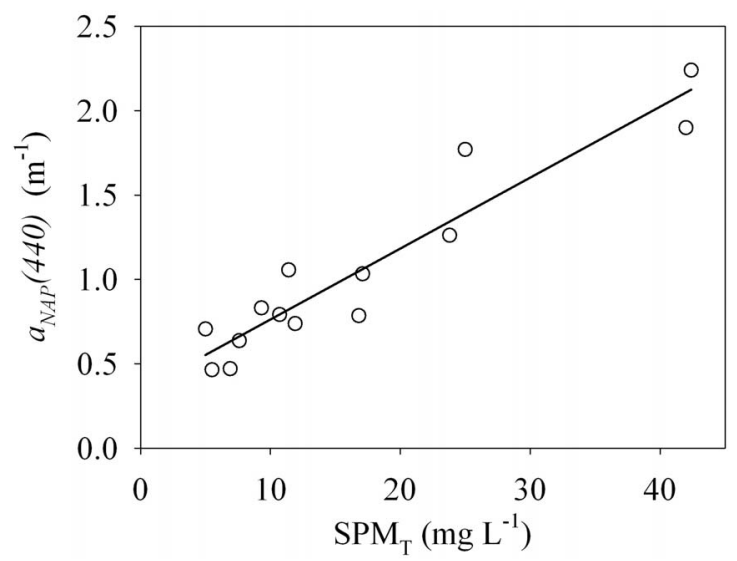

Figure 7. Relationship between absorption coefficient of nonalgal particles at $440 \mathrm{~nm}\left(a_{N A P}(440)\right)$ and total suspended particulate matter $\left(\mathrm{SPM}_{\mathrm{T}}\right)$. The line represents the linear regression model.

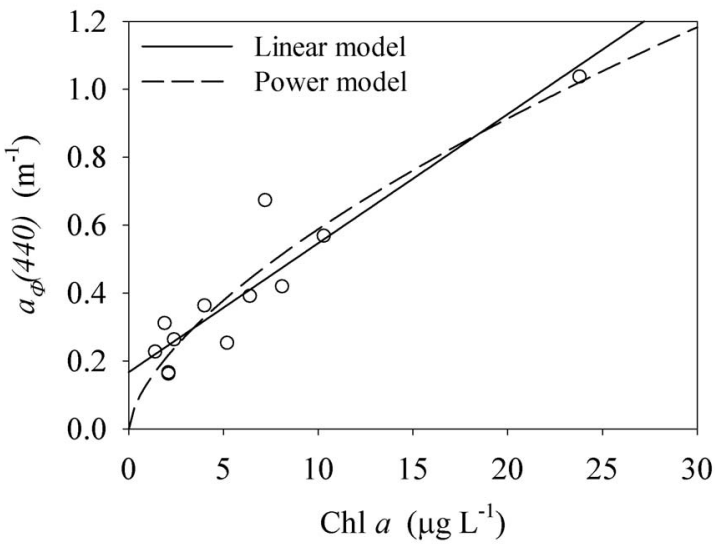

Figure 8. Relationship between chlorophyll $a$ concentration ( Chl $a$ ) and absorption coefficient of algal particles at $440 \mathrm{~nm}\left(a_{\Phi}(440)\right)$. The solid line represents the linear model, and the dashed line is for the power model applied to the data $(\mathrm{n}=12)$.

sion analysis was conducted to determine the relationships between total absorption and limnological variables, and forward stepwise regression analysis selected $\mathrm{SPM}_{\mathrm{T}}$ and DOC as explanatory variables, giving the model: $a_{t}(440)=$ $0.288 \mathrm{SPM}_{\mathrm{T}}+0.650 \mathrm{DOC}\left(\mathrm{r}^{2}=0.90\right.$, both $\mathrm{SPM}_{\mathrm{T}}$ and DOC were significant at $\mathrm{p}=0.05$ level, intercept not significantly different from zero).

\subsubsection{Scattering}

[37] The value of $b_{p}(555)$ ranged from 1.957 to $21.818 \mathrm{~m}^{-1}$ (mean: $7.345 \mathrm{~m}^{-1}$ ). At $440 \mathrm{~nm}$, the range was $2.595-$ $32.685 \mathrm{~m}^{-1}$ with a mean of $10.832 \mathrm{~m}^{-1}$. The $b_{p}(440)$ values were significantly correlated with variables related with nonalgal particles: $\mathrm{SPM}_{\mathrm{T}}(\mathrm{r}=0.97, \mathrm{p}<0.01), a_{N A P}(440)(\mathrm{r}=$ $0.93, \mathrm{p}<0.01)$, and $a_{\text {fine }}(440)(\mathrm{r}=0.99, \mathrm{p}<0.01)$, but not with algal particles: Chl $a(\mathrm{r}=-0.03, \mathrm{p}=0.90)$ and $a_{\Phi}(440)(\mathrm{r}=0.33, \mathrm{p}=0.25) . b_{p}^{*}(555)$ ranged from 0.300 to $0.688 \mathrm{~m}^{2} \mathrm{~g}^{-1}$ with a mean of $0.441 \mathrm{~m}^{2} \mathrm{~g}^{-1}$. Most of the scattering spectra showed a strong wavelength dependency represented by a hyperbolic model (Figure 10a). The spectrum of KWK 11 was the sole exception showing a departure from the hyperbolic curve in the range coinciding with photosynthetic pigment absorption (Figure 10b). The range of the hyperbolic exponent (n) was from 0.831 to 1.861 , with a mean of 1.545 excluding KWK 11 . The exponent significantly correlated with variables associated with suspended particulate matter concentrations: $\mathrm{SPM}_{\mathrm{T}}(\mathrm{r}=0.57, \mathrm{p}=0.02)$ and $\mathrm{SPM}_{\mathrm{I}}(\mathrm{r}=0.64, \mathrm{p}=0.01)$, and not with those representing dissolved organic carbon: $a_{C D O M}(440)(\mathrm{r}=0.25, \mathrm{p}=0.39)$ or DOC $(\mathrm{r}=0.16, \mathrm{p}=0.63)$. The single scattering albedo at $555 \mathrm{~nm}$ ranged from 0.814 to 0.921 (mean: 0.856), and the value decreased toward shorter wavelengths (Figure 11).

\subsection{Remote Sensing Analysis}

[38] The 34 ponds sampled in 2006 showed the same wide variety of conditions as those sampled in 2007, with DOC ranging from 3.8 to $12.9 \mathrm{mg} \mathrm{L}^{-1}$ and a mean of $8.6 \mathrm{mg} \mathrm{L}^{-1}$ (CV: $23 \%$ ), and $\mathrm{SPM}_{\mathrm{T}}$ from 1.8 to $55.2 \mathrm{mg} \mathrm{L}^{-1}$ with a mean of $19.8 \mathrm{mg} \mathrm{L}^{-1}$ (CV: 82\%). There was no significant correlation between these two limnological variables $(r=0.09$, $\mathrm{p}=0.61)$. The reflectance spectra showed relatively high 


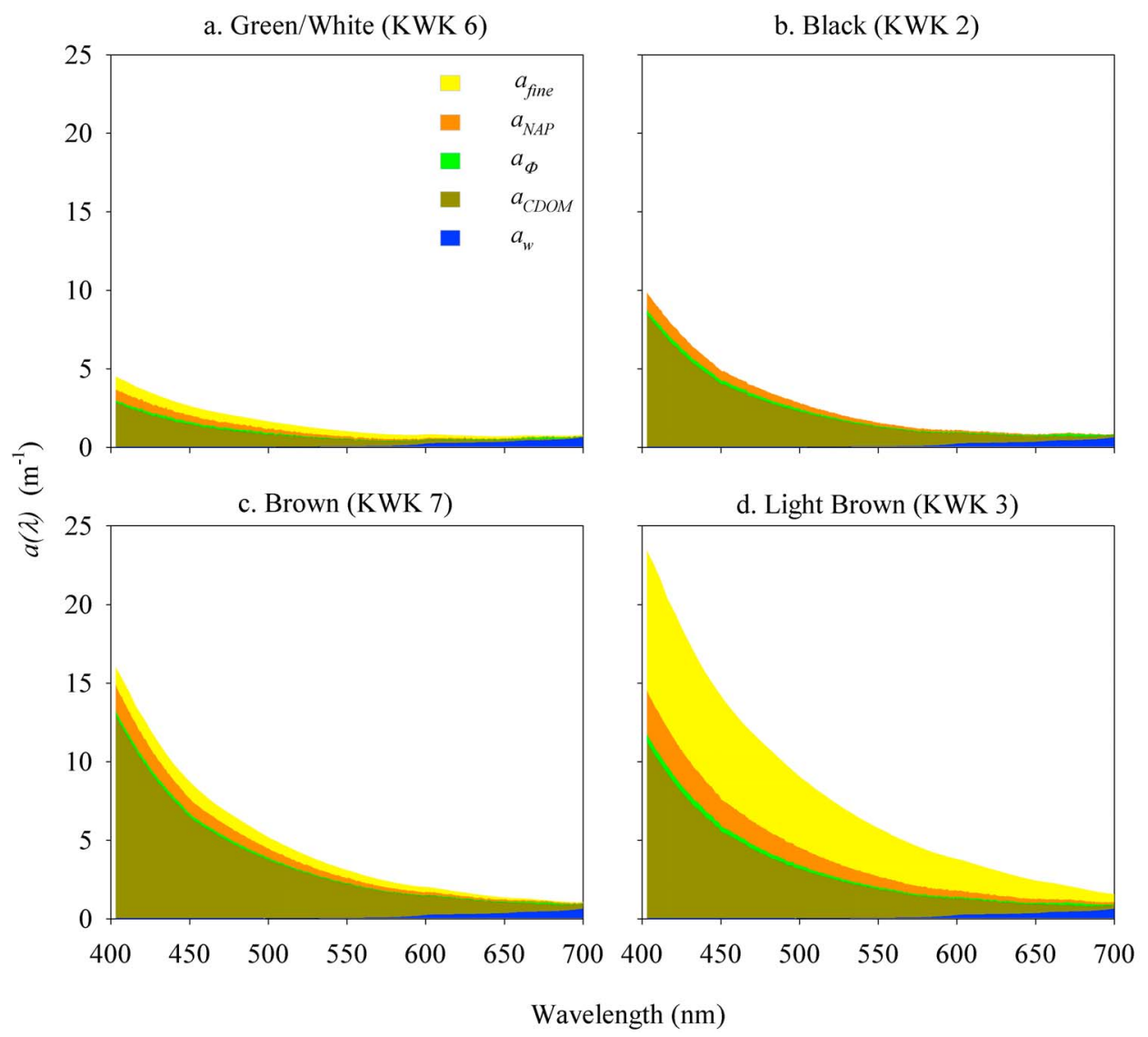

Figure 9. Examples of component absorption spectra for representative pond types: (a) low absorption pond with green or white color (KWK 6), (b) high dissolved absorption pond with black color (KWK 2), (c) high dissolved absorption pond with medium particulate absorption (KWK 7), and (d) high dissolved and particulate absorption pond (KWK 3 ).

values in the IR band (Figure 12). This may suggest that there was some influence from sun and sky glint or from adjacent land effects that are difficult to remove due to the limitations in current methodology. However, the shape of the reflectance spectra showed large differences among the observed ponds, and contained sufficient information for analysis of their wide variation in limnological conditions despite the uncertainties. The CCA provided the standardized coefficients to calculate canonical scores as shown in Table S1. Linear regression models between obtained canonical scores and limnological variables were significant for both $\operatorname{SPM}_{\mathrm{T}}\left(\mathrm{r}^{2}=0.78, \mathrm{p}<0.01\right)$ and DOC $\left(\mathrm{r}^{2}=0.35, \mathrm{p}<\right.$ $0.01)$. For the validation data set, the estimated and measured values from the regressions agreed well for both $\mathrm{SPM}_{\mathrm{T}}\left(\mathrm{r}^{2}=0.88, \mathrm{p}<0.01, \mathrm{RMSE}=6.27\right.$, slope $=1.02$,

Table 3. The Relative Contribution of Each Absorbing Component to Total Absorption at $440 \mathrm{~nm}$ (in \%) for All Sampled Thaw Ponds

\begin{tabular}{llcl}
\hline Variables & \multicolumn{1}{c}{ Range } & Mean & CV \\
\hline$a_{C D O M}(440)$ & $29-85$ & 65 & 26 \\
$a_{N A P}(440)$ & $8-21$ & 12 & 25 \\
$a_{\Phi}(440)$ & $2-14$ & 5 & 60 \\
$a_{\text {fine }}(440)$ & $0-53$ & 19 & 84 \\
$a_{w}(440)$ & $<0.2$ for all ponds & NA & NA \\
\hline
\end{tabular}

intercept not significantly different from zero; Figure 13a) and DOC $\left(\mathrm{r}^{2}=0.74, \mathrm{p}<0.01, \mathrm{RMSE}=1.20\right.$, slope $=1.05$, intercept not significantly different from zero; Figure 13b).

\section{Discussion}

[39] The striking variability in color among permafrost thaw ponds (Figure 2) implies large variations in their limnological properties, and our analyses provided clear evidence of such variability. DOC concentration, which would mostly originate from surrounding soils affected by permafrost [Breton et al., 2009], varied by a factor of three. Suspended particulate matter showed eightfold variation. It was dominated by nonalgal organic and inorganic suspended particulate matter in similar proportion among ponds, and the contribution of algal particles was minor. This nonalgal suspended particulate matter also likely originates from the surrounding soils, which are rich in clays and silts [Calmels et al., 2008b]. Chl a concentrations differed by a factor of 17; however, they were generally low, particularly by comparison with TP concentrations. The controlling mechanisms for this low $\mathrm{Chl} a$ to TP ratio are at present unknown, and future research is needed to address this observation. The wide variation in limnological conditions of nearby ponds may reflect differences in local topography, hydrology, and vegetation causing differential 


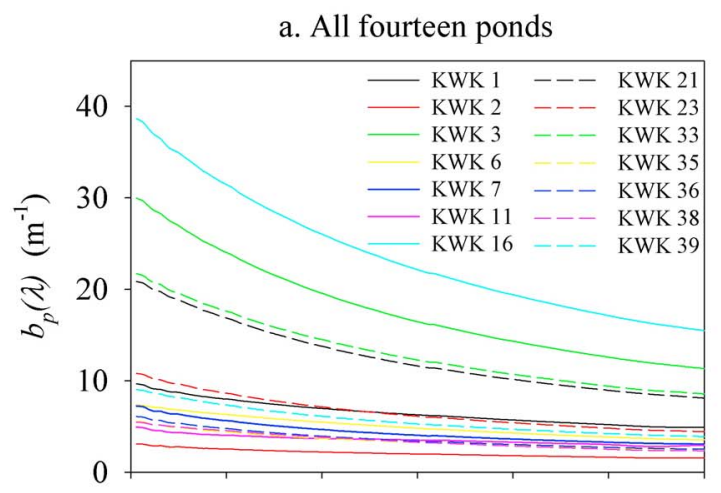

b. KWK 11

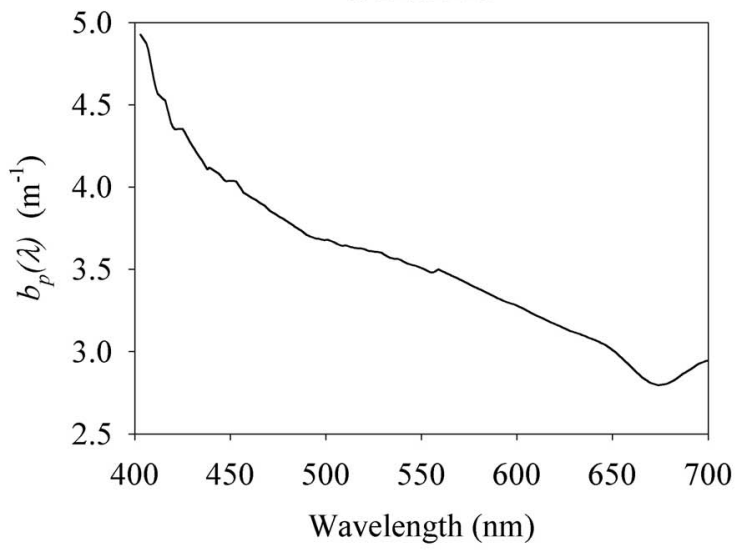

Figure 10. The particulate scattering coefficient spectra $\left(b_{p}(\lambda)\right)$ from 400 to $700 \mathrm{~nm}$ for (a) all 14 sampled ponds and (b) pond KWK 11 where $b_{p}(\lambda)$ was relatively low compared to other ponds and the influence of absorption by algal pigments was noticeable.

erosion, together with different developmental stages of the thermokarst [Calmels et al., 2008a; Pienitz et al., 2008]. To better understand mechanisms underlying this variability in nutrients, suspended particles, and DOC inputs, detailed studies regarding hydrology, geomorphology, and paleolimnology of these sites are required.

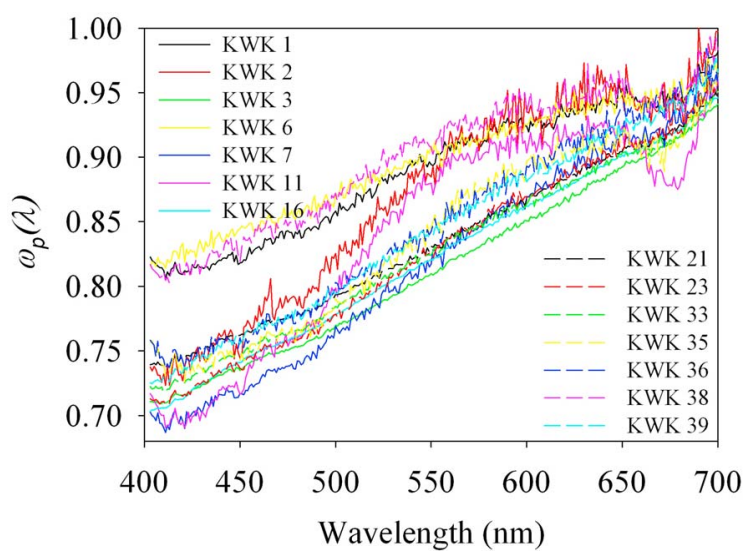

Figure 11. The single scattering albedo spectra $\left(\omega_{p}(\lambda)\right)$ for all 14 sampled ponds.

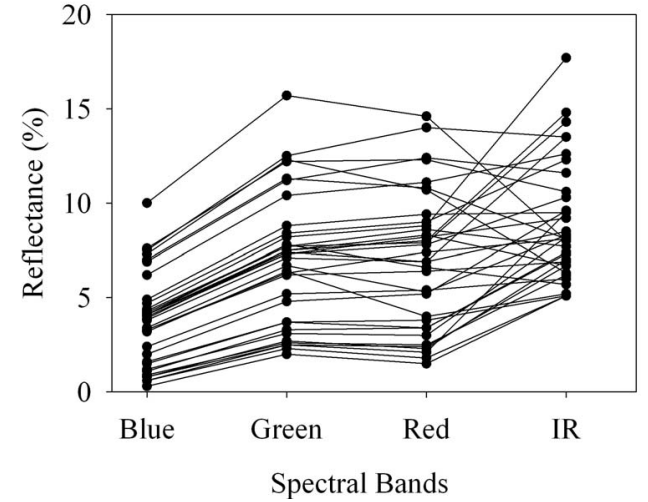

Figure 12. Reflectance spectra of the 34 ponds obtained from the Quickbird satellite image in July 2006.

[40] Our above-water spectroradiometric measurements captured the variation in visual appearance of the ponds (Figure 3), and their converted colorimetric values provided an appropriate analytical tool to numerically evaluate this variation in perceived color (Figure 4). Further, the relationship between color coordinate values and limnological variables helped to elucidate the underlying mechanisms controlling this observed variation. These results support the use of above-water AOPs to describe the color of case 2 waters. Such an approach continues to offer much potential in water color evaluation and prediction for water resource management.

[41] Our analysis of these optically diverse thaw ponds showed that color is determined by the specific mixture of DOC and $\mathrm{SPM}_{\mathrm{T}}$. More precisely, the green to red color transition $\left(a^{*}\right.$ axis) was controlled by DOC concentrations that represent CDOM absorption (discussed below). Due to the absorption spectral shape (Figure 5a), blue light was strongly absorbed even at low DOC concentrations, while green light was still perceivable. Along with the increase in DOC, green light was also strongly absorbed, and water color shifted toward red. The magnitude of transition on this axis was small relative to that of other axes; however, the observed values were distributed in both the green (negative $a^{*}$ ) and red (positive $a^{*}$ ) quadrants. Thus, this transition considerably influenced the pond color as perceived by the human eye.

[42] The blue to yellow transition $\left(b^{*}\right)$ and lightness $\left(L^{*}\right)$ were controlled by the DOC:SPM $\mathrm{T}_{\mathrm{T}}$ ratio, which may represent the ratio of dissolved absorption and scattering (see below). Light scattering contributed to the upward flux of light back to surface and atmosphere, while absorption did the opposite. The balance of these two functions dictates the amount of surface leaving radiation, i.e., the perceived lightness of the waterbodies. This function was pronounced at the yellow to red end of the spectrum where absorption was low relative to the blue-green wave band; thus, yellowness as well as lightness increased as a function of decreasing DOC:SPM $\mathrm{T}$.

[43] The observed range in CDOM absorption was surprisingly wide, especially for such closely located ponds. Detailed analyses on optical properties suggest that the wide variation in CDOM would be due mostly to quantitative 

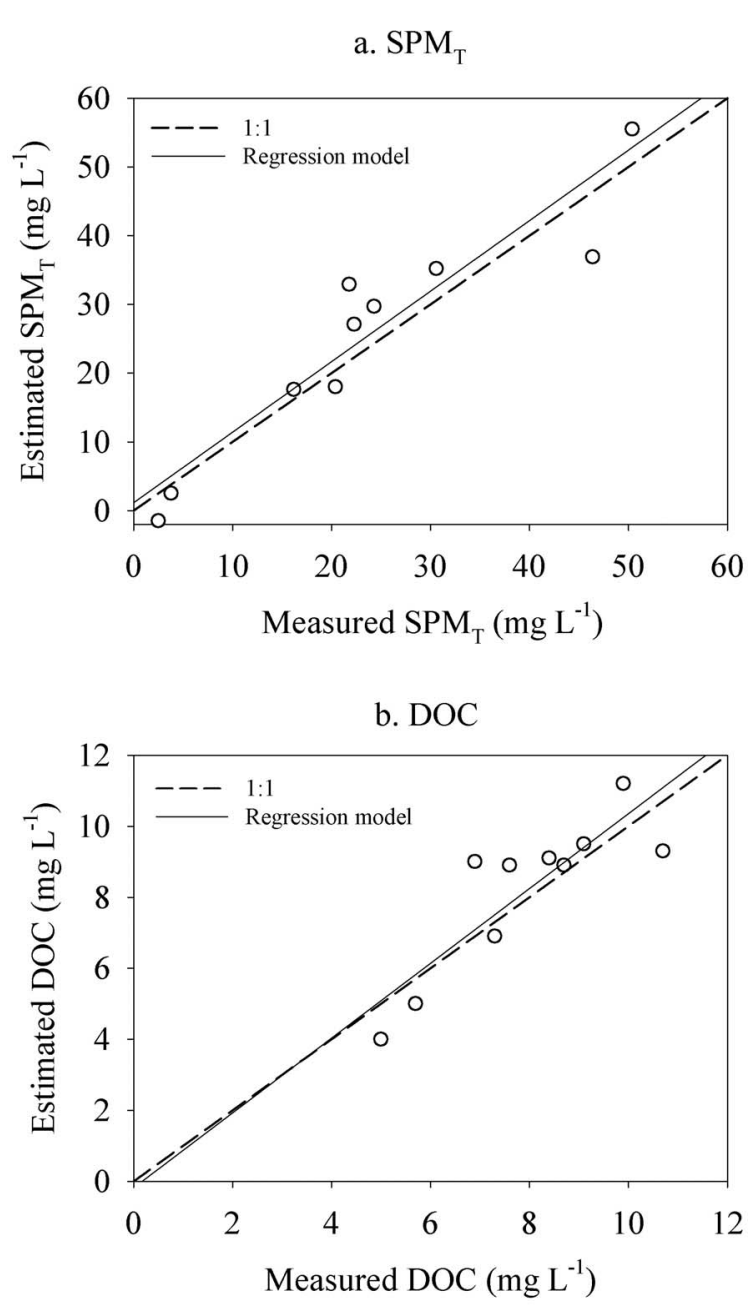

Figure 13. Comparison of measured to estimated values of (a) total suspended particulate matter $\left(\mathrm{SPM}_{\mathrm{T}}\right)$ and (b) dissolved organic carbon (DOC) for the validation data set $(\mathrm{n}=10)$ when applying the canonical model. Solid lines show the regression model, and dashed lines show the one-to-one relationship.

differences in the DOC pool, not to qualitative differences. $S_{C D O M}$, a variable characterizing the shape of CDOM absorption curves that is often considered as an indicator of DOC composition in natural waters [Stedmon et al., 2000; Zepp et al., 2008], showed relatively low values with narrower range compared to the values in other natural waters [Markager and Vincent, 2000]. Also, the range in $a_{C D O M}^{*}(440)$, another variable indicating DOC composition [Morris et al., 1995], was much narrower than that reported in other inland waterbodies [Bukaveckas and Robbins Forbes, 2000; Morris et al., 1995; Watanabe et al., 2009]. The observed low variability in these variables despite wide variation in absolute absorption indicates a strong similarity in the chemical composition of the DOC pool among ponds. This result is consistent with DOC fluorescence analysis by Breton et al. [2009] suggesting that the DOC in these ponds was of similar terrigenous origin.

[44] The compositional similarity and optical resemblance of the DOC pool in these permafrost thaw ponds increases the prospect of inferring DOC concentrations from optical information. Significant correlations between DOC and CDOM have been previously documented [e.g., Bukaveckas and Robbins-Forbes, 2000; Pace and Cole, 2002] and such relationships can be used to estimate CDOM [e.g., Pienitz and Vincent, 2000] and to predict the attenuation of ultraviolet radiation (UVR) [e.g., Morris et al., 1995; Scully and Lean, 1994] from DOC concentration, or vice versa. These applications, however, would be valid only when the composition of the DOC pool is similar among waterbodies [Watanabe et al., 2009]. In our study sites, a strong DOCCDOM relationship (Figure 6) was observed, although the lack of observations at low concentrations precludes the application of a power model as in the work of Bukaveckas and Robbins-Forbes [2000]. The clear relationship within the observed range, as well as compositional similarity of the DOC pool noted above suggest that optical measurements, including spectrophotometry and remote sensing, would be a useful approach to estimate DOC and UVR attenuation. Algorithms from this region, however, should be applied with caution elsewhere, given the observed differences in DOC composition in other thaw pond regions [Breton et al., 2009].

[45] Most thaw ponds contained high concentrations of suspended particulate matter, and NAP absorption values lay at or above the range that has been previously observed in coastal marine waters [Babin et al., 2003b] but lower than that of the upper bound for eutrophic lakes [Sun et al., 2009; Zhang et al., 2010]. In addition, the specific absorption characteristics of the particles found in thaw ponds may contribute to their high $a_{N A P}(440)$ values. The slope of $a_{N A P}(440)-\mathrm{SPM}_{\mathrm{T}}$ model $(0.042)$ was more than $35 \%$ higher than that reported elsewhere (0.031 [Babin et al., 2003b], 0.0235 [Bowers et al., 1996], 0.0214 [Binding et al., 2008]). Also, the mean $a_{N A P}^{*}(440)\left(0.073 \mathrm{~m}^{2} \mathrm{~g}^{-1}\right.$; Table 2) was higher than found elsewhere (0.05 [Belzile et al., 2004], 0.041 [Babin et al., 2003b], 0.040 [Binding et al., 2008]). These results suggest that NAP in thaw ponds have unusually high mass-specific absorption properties. Three possible explanations may account for this. First, particle size is an important determinant of absorption characteristics of suspended particles in natural waters [Stramski et al., 2007]. The surrounding permafrost soils, likely to be the main source of suspended particles for these ponds, contain mostly fine clay particles [Calmels et al., 2008b]. Because of their small size, these particles may cause higher absorption due to the particle package effect [Stramski et al., 2007]. Second, the composition of NAP is also an important determinant of $a_{N A P}(\lambda)$ characteristics [Babin et al., 2003b; Binding et al., 2008]. Absorption by the organic component of NAP, including both algal and terrigenous detritus, is incorporated into $a_{N A P}(\lambda)$. In our study sites, organic component quantified as $\mathrm{SPM}_{\mathrm{O}}$ largely accounted for $\mathrm{SPM}_{\mathrm{T}}$ (30\% on average), and absorption characteristics of this fraction may contribute the high specific absorption of NAP in thaw ponds. Finally, CDOM adsorbed onto NAP might cause higher absorptions. $S_{N A P}$ values were negatively correlated with $a_{C D O M}(440)(\mathrm{r}=-0.59, \mathrm{p}=0.03)$, indicating that the concentration of CDOM might have an influence on $a_{N A P}(\lambda)$ absorption spectra.

[46] Although NAP showed unusually high mass-specific absorption and large variation in absorption among ponds, 
its mass-specific absorption $\left(a_{N A P}^{*}(440)\right)$ and shape of absorption spectra $\left(S_{N A P}\right)$ showed little variation among ponds. Also, there was a strong relationship between $a_{N A P}(440)$ and $\mathrm{SPM}_{\mathrm{T}}$ for these waterbodies. These results suggest compositional similarity and optical resemblance of NAP of the ponds in the studied area. Similar to $a_{C D O M}(\lambda)$ discussed above, the variation in $a_{N A P}(\lambda)$ would be due to the quantitative difference of particles in the water column, suggesting that optical estimation of $\mathrm{SPM}_{\mathrm{T}}$ would be feasible, as for DOC. Furthermore, there was a strong correlation between $\mathrm{SPM}_{\mathrm{T}}$ and TP in the ponds $(\mathrm{r}=0.84, \mathrm{p}<$ $0.01, \mathrm{n}=33,2006$ data), implying that an optical estimation of nutrient content (TP) may also be possible [Kutser et al., 1995].

[47] The absorption by algal particles showed a wide range of values among ponds (Figure 8), and the increase of $a_{\Phi}(440)$ per unit Chl $a$ was higher (i.e., the relationship had a steeper slope) relative to those previously reported in freshwater systems [Perkins et al., 2009; Sun et al., 2009; Zhang et al., 2010] and oceanic systems [Bricaud et al., 1995; Matsuoka et al., 2007]. Furthermore, the mean value of $a_{\Phi}^{*}(440)$ was above previously reported values [Bricaud et al., 1995; Dekker et al., 2002; Zhang et al., 2010]. These observations imply that the pigment composition in thaw pond phytoplanktonic communities differs greatly from that of other natural waterbodies. However, it has been reported that particulate humic color extracted by methanol may induce overestimation of $a_{\Phi}(\lambda)$ in waterbodies with high concentrations of NAP [Gallegos, 2005]. Additionally, the observed range of $a_{\Phi}(440)$ and Chl $a$ in the present study may be too narrow to appropriately evaluate the model and $a_{\Phi}^{*}(440)$, and more detailed analysis with larger data sets is required.

[48] In the present study, we defined fine particles as those passing through $\mathrm{GF} / \mathrm{F}$ filters and then caught on cellulose acetate filters. The size range of these particles is therefore assumed to be $0.2-0.7 \mu \mathrm{m}$. Suspended particles in this size range may have important implications for aquatic ecosystems by causing light limitation of algal growth in highly turbid waterbodies [Knowlton and Jones, 2000]. The optical property of fine particles suspended in natural waters, however, has been little examined [Gallegos, 2005; Stramski and Wozniak, 2005; Stramski et al., 2007]. In our study sites, fine particle absorption was always observed except in ponds with the lowest suspended particulate matter concentrations. Most of these fine particles were probably inorganic, and derived from the surrounding soils rich in clays [Calmels et al., 2008b]. Phytoplankton particles would have had little contribution to the measured absorption values because no Chl $a$ peaks at 440 or $680 \mathrm{~nm}$ were apparent in the spectra. The mass-specific absorption of fine particles has important implications for future parameterization of optical properties of these ponds, and may be higher than that of larger particles due to size-dependent effects [Stramski et al., 2007]. This could not, however, be appropriately quantified from the current data set because of uncertainty in precision of $a_{\text {fine }}(\lambda)$ estimation due to the methodological limitations discussed above, and the absence of dry weight measurements of the fine particle fraction. Careful evaluation of analytical methods for measuring $a_{\text {fine }}(\lambda)$ spectra [Ferrari and Tassan, 1996; Gallegos, 2005] is required in future studies of such fine particle containing systems.

[49] The influence of fine particles on estimation of $\mathrm{SPM}_{\mathrm{T}}$ by optical measurements in the study sites can be regarded as a minor factor, although the detailed optical characteristics of this component remain unknown. The strong linear relationships between $a_{\text {fine }}(440)$ and measures of suspended particles caught on $\mathrm{GF} / \mathrm{F}$ filters, $\mathrm{SPM}_{\mathrm{T}}$ and $a_{N A P}(440)$, showed that the concentration of fine particles increased in tandem with larger particle concentrations and absorption. This result suggests that the influence of fine particles can be accounted for by measuring larger particles with conventional methods.

[50] As a result of the large variation in each absorbing component, $a_{t}(\lambda)$ showed a fivefold variation (Table 2 ), and the proportional contribution of each component to $a_{t}(\lambda)$ also varied greatly (Figure 9 and Table 3). Overall, CDOM was the dominant absorption factor in most ponds, and was only a lesser component in those ponds where fine particles dominated. The absorption by suspended particulate matter caught on glass fiber filters, measured as $a_{N A P}(\lambda)$ and $a_{\Phi}(\lambda)$, played a lesser role in the spectra of all ponds. In particular, the contribution of algal particles was minor (less than $15 \%$ for all ponds). In contrast to absorption by those larger particles, fine particles played an important role in ponds with high suspended particulate matter concentrations (Figure 9d).

[51] Estimation of Chl $a$ by remotely sensed data is well developed and commonly applied to oceanic case 1 waters, where it is a major light-absorbing component as well as highly correlated with other absorbing components [Morel, 1988]. This approach, however, will not be successful in our study sites, as algal particles exhibited a negligible role in the absorption spectra and varied independently of other optically active components. Instead, the two dominant absorbing factors, CDOM and fine particles, were strongly related to $\mathrm{DOC}$ and $\mathrm{SPM}_{\mathrm{T}}$ concentrations, respectively. Therefore, the estimation of these two variables from optical data should be feasible for this system.

[52] Few data are available for spectral scattering coefficients in freshwater ecosystems and the present study increases the availability of such information. There was large variation in these values among ponds, and within the range previously observed by similar instruments (AC-9, WET Labs Inc., USA) in coastal [Babin et al., 2003a; Doxaran et al., 2009] and riverine systems [Gallegos, 2005]. The characteristics of $b_{p}(\lambda)$ spectra and their relationship with limnological variables well portrayed the characteristics of scattering components at our study sites, which is consistent with the results of the particulate absorption analyses, as discussed above. First, the correlation analyses and the shapes of scattering spectra, well represented by the hyperbolic model described by equation (9), indicated that nonalgal suspended particulate matter dominated scattering, and that algal particles played a minor role, as in coastal marine waters [Babin et al., 2003a]. The only exception was a pond with high Chl $a$ concentrations (KWK 11) where the influence of algal pigment absorption on the scattering spectra was observed. Second, the obtained hyperbolic exponents (mean: 1.545) were higher relative to previously reported values in coastal waters [Doxaran et al., 2009]. 
A theoretical study suggested that this exponent represents the size distribution of scattering particles when the distribution is assumed to follow the Junge type power law, and that the exponent increases as a function of the proportion of small size particles in the total scattering particle population [see Babin et al., 2003a, and references therein]. In the present study, the values did indeed show a strong positive correlation with the proportion of $a_{\text {fine }}(440)$ in the total particulate absorption $\left(a_{t-w}(440)-a_{C D O M}(440) ; \mathrm{r}=0.82\right.$, $\mathrm{p}<0.01)$. This result is consistent with the theoretically simulated particle size distribution [see Babin et al., 2003a, Figure 4], and implies the domination of small size particles in thaw pond scattering. Finally, the spectral shape of $\omega_{p}(\lambda)$ showed a strong influence of absorption at the blue end of scattering spectra. In summary, scattering processes in the studied systems were dominated by small nonalgal particles having high absorption characteristics.

[53] The $\mathrm{SPM}_{\mathrm{T}}$ specific scattering coefficients were similar to those for coastal waters and to theoretically predicted values for inorganic particles [Babin et al., 2003a; Doxaran et al., 2009]. However, these values must be interpreted with caution. The fraction of particles accounted for by our two measurements differed; $b_{p}(\lambda)$ accounted all particles in the water column but $\mathrm{SPM}_{\mathrm{T}}$ was assumed to include only particles larger than $0.7 \mu \mathrm{m}$. Fine particles likely make a substantial contribution to the total mass of suspended particulate matter. Inclusion of dry weight of this size fraction into the $b_{p}^{*}(\lambda)$ calculation would result in lower mass-specific values especially for highly turbid systems, which may affect subsequent optical modeling. Turbid systems therefore require a much closer analysis of particle size distribution, as well as attention to the optical characteristics of fine particles.

[54] Our results suggest that high spatial resolution multispectral satellite imagery may be a useful tool for estimating limnological properties of permafrost thaw ponds, which are abundant and widely distributed over remote and poorly accessible areas. Remote sensing techniques have already been applied to inland waterbodies where smallscale spatial heterogeneity has important implications for water resource management [e.g., Oyama et al., 2009; Tyler et al., 2006]. The present results also show an application to small-scale systems, specifically inland waterbodies with high intersystem variation in limnological conditions, as small as $10 \mathrm{~m}$ in diameter. The goodness of fit of the CCA modeling indicates that two optically important constituents, DOC and $\mathrm{SPM}_{\mathrm{T}}$, can be derived from satellite imagery using multivariate statistical modeling. These two variables would provide useful information not only on optical processes but also on the biogeochemical cycles of the systems. DOC is of special interest since it has important implications for microbial processes, including greenhouse gas emissions from these waterbodies [Laurion et al., 2010; Sobek et al., 2005]. Furthermore, both optically active constituents can regulate photosynthetic production by strongly attenuating light in the water column [Karlsson et al., 2009; Knowlton and Jones, 2000; Vincent et al., 1996]. Therefore, remote sensing techniques have the potential to estimate the significance of biological activity in thaw ponds within the global carbon cycle $(\mathrm{P} / \mathrm{R}$ balance, greenhouse gas production, and underwater UVR exposure). For future applications of such models, validation is required based on larger data sets covering disparate geographic areas with potentially different limnological and optical characteristics.

\section{Conclusions}

[55] Thaw ponds in the discontinuous permafrost region of Nunavik, Canada showed a wide variety of optical conditions that were strikingly apparent as differences in water color. This variation is largely the result of variable combinations of dissolved organic carbon and nonalgal suspended particulate matter concentrations in the water column. Analyses of IOPs of waterbodies showed that compositions of these optically important components were similar among ponds; i.e., the optical diversity was derived from their variation in concentrations but not composition. Analysis of high spatial resolution multispectral satellite imagery of these ponds showed that these two optically important constituents could be remotely estimated by multivariate modeling. Given the importance of these two constituents in aquatic biogeochemical cycles, remote sensing surveys will provide valuable synoptic observations of permafrost thaw ponds across the vast subarctic regions, and may allow scaling up of the local greenhouse gas flux measurements to regional and circumpolar scales.

[56] Acknowledgments. We thank T. Harding, F. Bouchard, J. Breton, C. Dupont, L. Retamal, and A. Rouillard for their assistance with field work and laboratory analyses, and R. Fillion for the satellite image treatment and extraction of spectral signature. We also thank M. Babin (CNRS, France) for valuable comments on the manuscript. This research was funded by Le Fonds Québécois de la recherche sur la nature et les technologies (FQRNT), the Natural Sciences and Engineering Research Council of Canada (NSERC), the Networks of Centres of Excellence program ArcticNet, and the Canada Research Chair program.

\section{References}

Arrigo, K. R., G. L. van Dijken, and S. Bushinsky (2008), Primary production in the Southern Ocean, 1997-2006, J. Geophys. Res., 113, C08004, doi:10.1029/2007JC004551.

Babin, M., A. Morel, V. Fournier-Sicre, F. Fell, and D. Stramski (2003a), Light scattering properties of marine particles in coastal and open ocean waters as related to the particle mass concentration, Limnol. Oceanogr., $48,843-859$.

Babin, M., D. Stramski, G. M. Ferrari, H. Claustre, A. Bricaud, G. Obolensky, and N. Hoepffner (2003b), Variations in the light absorption coefficients of phytoplankton, nonalgal particles, and dissolved organic matter in coastal waters around Europe, J. Geophys. Res., 108(C7), 3211, doi:10.1029/ 2001JC000882.

Belzile, C., W. F. Vincent, C. Howard-Williams, I. Hawes, M. James, M. Kumagai, and C. Roesler (2004), Relationships between spectral optical properties and optically active substances in a clear oligotrophic lake, Water Resour. Res., 40, W12512, doi:10.1029/2004WR003090.

Binding, C. E., J. H. Jerome, R. P. Bukata, and W. G. Booty (2008), Spectral absorption properties of dissolved and particulate matter in Lake Erie, Remote Sens. Environ., 112, 1702-1711.

Bowers, D. G., G. E. L. Harker, and B. Stephan (1996), Absorption spectra of inorganic particles in the Irish Sea and their relevance to remote sensing of chlorophyll, Int. J. Remote Sens., 17, 2449-2460.

Breton, J., C. Vallieres, and I. Laurion (2009), Limnological properties of permafrost thaw ponds in northeastern Canada, Can. J. Fish. Aquat. Sci., 66, 1635-1648.

Bricaud, A., A. Morel, and L. Prieur (1981), Absorption by dissolved organic-matter of the sea (yellow substance) in the UV and visible domains, Limnol. Oceanogr., 26, 43-53.

Bricaud, A., M. Babin, A. Morel, and H. Claustre (1995), Variability in the chlorophyll-specific absorption-coefficients of natural phytoplankton: Analysis and parameterization, J. Geophys. Res., 100, 13,321-13,332.

Bukaveckas, P. A., and M. Robbins-Forbes (2000), Role of dissolved organic carbon in the attenuation of photosynthetically active and ultraviolet radiation in Adirondack lakes, Freshwater Biol., 43, 339-354. 
Calmels, F., M. Allard, and G. Delisle (2008a), Development and decay of a lithalsa in Northern Quebec: A geomorphological history, Geomorphology, 97, 287-299.

Calmels, F., G. Delisle, and M. Allard (2008b), Internal structure and the thermal and hydrological regime of a typical lithalsa: Significance for permafrost growth and decay, Can. J. Earth Sci., 45, 31-43.

Cohen, W. B., T. K. Maiersperger, S. T. Gower, and D. P. Turner (2003), An improved strategy for regression of biophysical variables and Landsat ETM+ data, Remote Sens. Environ., 84, 561-571.

Commission Internationale d'Éclairage (CIE) (1931), CIE 1931 Standard Colorimetric Observer, Vienna.

Commission Internationale d'Éclairage (CIE) (1986), CIE Standard Illuminant D65 relative spectral power distribution (CIE 15.2-1986 Table 1.1, Part 2), Vienna.

Dekker, A. G., R. J. Vos, and S. W. M. Peters (2002), Analytical algorithms for lake water TSM estimation for retrospective analyses of TM and SPOT sensor data, Int. J. Remote Sens., 23, 15-35.

Doxaran, D., K. Ruddick, D. McKee, B. Gentili, D. Tailliez, M. Chami, and M. Babin (2009), Spectral variations of light scattering by marine particles in coastal waters, from visible to near infrared, Limnol. Oceanogr., 54, 1257-1271.

Duntley, S. Q. (1963), Light in the sea, J. Opt. Soc. Am., 53, 214-233.

Ferrari, G. M., and S. Tassan (1996), Use of the $0.22 \mu \mathrm{m}$ Millipore membrane for light-transmission measurements of aquatic particles, J. Plankton Res., 18, 1261-1267.

Ferrari, G. M., and S. Tassan (1999), A method using chemical oxidation to remove light absorption by phytoplankton pigments, J. Phycol., 35, 1090-1098

Flink, P., T. Lindell, and C. Ostlund (2001), Statistical analysis of hyperspectral data from two Swedish lakes, Sci. Total Environ., 268, 155-169.

Gallegos, C. L. (2005), Optical water quality of a blackwater river estuary: The Lower St. Johns River, Florida, USA, Estuarine Coastal Shelf Sci., $63,57-72$

Gallegos, C. L., and P. J. Neale (2002), Partitioning spectral absorption in case 2 waters: Discrimination of dissolved and particulate components, Appl. Opt., 41, 4220-4233.

Heiskanen, J. (2006), Estimating aboveground tree biomass and leaf area index in a mountain birch forest using ASTER satellite data, Int. J. Remote Sens., 27, 1135-1158.

International Ocean-Colour Coordinating Group (IOCCG) (1999), Status and plans for satellite ocean-color missions: Considerations for complementary missions, 40 pp., Dartmouth, N. S., Canada.

International Ocean-Colour Coordinating Group (IOCCG) (2000), Remote sensing of ocean colour in coastal, and optically complex, waters, $140 \mathrm{pp}$., Dartmouth, N. S., Canada.

Johnson, R. A., and D. W. Wichern (2007), Applied Multivariate Statistical Analysis, 6th ed., 800 pp., Prentice Hall, Upper Saddle River, N. J.

Karlsson, J., P. Bystrom, J. Ask, P. Ask, L. Persson, and M. Jansson (2009), Light limitation of nutrient-poor lake ecosystems, Nature, 460, 506-509.

Kirk, J. T. O. (1992), Monte-Carlo modeling of the performance of a reflective tube absorption meter, Appl. Opt., 31, 6463-6468.

Kishino, M., M. Takahashi, N. Okami, and S. Ichimura (1985), Estimation of the spectral absorption-coefficients of phytoplankton in the sea, Bull. Mar. Sci., 37, 634-642.

Knowlton, M. F., and J. R. Jones (2000), Non-algal seston, light, nutrients and chlorophyll in Missouri reservoirs, Lake Reservior Manage., 16, 322-332.

Kutser, T., H. Arst, T. Miller, L. Kaarmann, and A. Milius (1995), Telespectrometrical estimation of water transparency, chlorophyll-a and total phosphorus concentration of Lake Peipsi, Int. J. Remote Sens., 16, 3069-3085.

Laurion, I., W. F. Vincent, S. MacIntyre, L. Retamal, C. Dupont, P. Francus, and R. Pienitz (2010), Variability in greenhouse gas emissions from permafrost thaw ponds, Limnol. Oceanogr., 55, 115-133.

Li, R. R., Y. J. Kaufman, B. C. Gao, and C. O. Davis (2003), Remote sensing of suspended sediments and shallow coastal waters, IEEE Trans. Geosci. Remote Sens., 41, 559-566.

Markager, S., and W. F. Vincent (2000), Spectral light attenuation and the absorption of UV and blue light in natural waters, Limnol. Oceanogr., 45, 642-650.

Matsuoka, A., Y. Huot, K. Shimada, S. I. Saitoh, and M. Babin (2007), Biol.-optical characteristics of the western Arctic Ocean: Implications for ocean color algorithms, Can. J. Rem. Sens., 33, 503-518.

Mitchell, B. G., et al. (2000), Determination of spectral absorption coefficients of particles, dissolved material and phytoplankton for discrete water samples, in Ocean Optics Protocols for Satellite Ocean Color Sensor Validation, Revision 2, edited by G. S. Fargion and J. L. Mueller, pp. 125-153, NASA, Greenbelt, Md.
Mitchell, B. G., M. Kahru, J. Wieland, and M. Stramska (2002), Determination of spectral absorption coefficients of particles, dissolved material and phytoplankton for discrete water samples, in Ocean Optics Protocols for Satellite Ocean Color Sensor Validation, Revision 4, edited by J. L. Mueller and G. S. Fargion, pp. 39-64, NASA, Greenbelt, Md.

Mobley, C. D. (1999), Estimation of the remote-sensing reflectance from above-surface measurements, Appl. Opt., 38, 7442-7455.

Morel, A. (1988), Optical modeling of the upper ocean in relation to its biogenous matter content (case I waters), J. Geophys. Res., 93, 10,749-10,768.

Morris, D. P., H. Zagarese, C. E. Williamson, E. G. Balseiro, B. R. Hargreaves, B. Modenutti, R. Moeller, and C. Queimalinos (1995), The attentuation of solar UV radiation in lakes and the role of dissolved organic carbon, Limnol. Oceanogr., 40, 1381-1391.

Mueller, J. L., C. Davis, R. Arnone, R. Frouin, K. Carder, Z. P. Lee, R. G. Steward, S. Hooker, C. D. Mobley, and S. McLean (2002), Above-water radiance and remote sensing reflectance measurement and analysis protocols, in Ocean Optics Protocols for Satellite Ocean Color Sensor Validation, Revision 4, edited by J. L. Mueller and G. S. Fargion, pp. 21-32, NASA, Greenbelt, Md

Nusch, E. A. (1980), Comparison of different methods for chlorophyll and phaeopigment determination, Arch. Hydrobiol., 14, 14-36.

Oyama, Y., and A. Shibahara (2009), Simulation of water colors in a shallow acidified lake, Lake Onneto, Japan, using colorimetric analysis and bio-optical modeling, Limnology, 10, 47-56.

Oyama, Y., B. Matsushita, T. Fukushima, K. Matsushige, and A. Imai (2009), Application of spectral decomposition algorithm for mapping water quality in a turbid lake (Lake Kasumigaura, Japan) from Landsat TM data, ISPRS J. Photogramm. Remote Sens., 64, 73-85.

Pace, M. L., and J. J. Cole (2002), Synchronous variation of dissolved organic carbon and color in lakes, Limnol. Oceanogr., 47, 333-342.

Pegau, S., J. R. V. Zaneveld, B. G. Mitchell, J. L. Mueller, M. Kahru, J. Wieland, and M. Stramska (2003), Inherent optical properties: Instruments, characterizations, field measurements and data analysis protocols, in Ocean Optics Protocols for Satellite Ocean Color Sensor Validation; Revision 4, edited by J. L. Mueller, G. S. Fargion, and R. McClain, NASA, Greenbelt, Md.

Perkins, M., S. W. Effler, C. Strait, and L. Zhang (2009), Light absorbing components in the Finger Lakes of New York, Arch. Hydrobiol., 173, 305-320.

Pienitz, R., and W. F. Vincent (2000), Effect of climate change relative to ozone depletion on UV exposure in subarctic lakes, Nature, 404, 484-487.

Pienitz, R., P. T. Doran, and S. F. Lamoureux (2008), Origin and geomorphology of lakes in the polar regions, in Polar Lakes and Rivers: Limnology of Arctic and Antarctic Aquatic Ecosystems, edited by W. F. Vincent and J. Laybourn-Parry, pp. 25-41, Oxford Univ. Press, Oxford, U. K.

Ping, C. L., G. J. Michaelson, M. T. Jorgenson, J. M. Kimble, H. Epstein, V. E. Romanovsky, and D. A. Walker (2008), High stocks of soil organic carbon in the North American Arctic region, Nat. Geosci., 1, 615-619.

Pope, R. M., and E. S. Fry (1997), Absorption spectrum (380-700 nm) of pure water.2. Integrating cavity measurements, Appl. Opt., 36, 8710-8723.

R Development Core Team (2009), R: A language and environment for statistical computing, R Found. for Stat. Comput., Vienna.

Roesler, C. S. (1998), Theoretical and experimental approaches to improve the accuracy of particulate absorption coefficients derived from the quantitative filter technique, Limnol. Oceanogr., 43, 1649-1660.

Schanda, J. (2007), CIE colorimetry, in Colorimetry: Understanding the CIE System, edited by J. Schanda, pp. 25-78, Wiley-Interscience, Hoboken, N. J.

Scully, N. M., and D. R. S. Lean (1994), The attenuation of ultraviolet radiation in temperate lakes, Ergebnisse Limnol., 43, 135-144.

Simis, S. G. H., S. W. M. Peters, and H. J. Gons (2005), Remote sensing of the cyanobacterial pigment phycocyanin in turbid inland water, Limnol. Oceanogr., 50, 237-245.

Sobek, S., L. J. Tranvik, and J. J. Cole (2005), Temperature independence of carbon dioxide supersaturation in global lakes, Global Biogeochem. Cycles, 19, GB2003, doi:10.1029/2004GB002264.

Stainton, M. P., M. J. Capel, and F. A. J. Armstrong (1977), The chemical analysis of freshwater, 2nd ed., Can. Fish. Mar. Serv. Misc. Spec. Publ. 25, 180 pp., Freshwater Inst., Winnipeg, Manitoba, Canada.

Stedmon, C. A., S. Markager, and H. Kaas (2000), Optical properties and signatures of chromophoric dissolved organic matter (CDOM) in Danish coastal waters, Estuarine Coastal Shelf Sci., 51, 267-278.

Stramski, D., and S. B. Wozniak (2005), On the role of colloidal particles in light scattering in the ocean, Limnol. Oceanogr., 50, 1581-1591.

Stramski, D., M. Babin, and S. B. Wozniak (2007), Variations in the optical properties of terrigenous mineral-rich particulate matter suspended in seawater, Limnol. Oceanogr., 52, 2418-2433.

Sullivan, J. M., M. S. Twardowski, J. R. V. Zaneveld, C. M. Moore, A. H. Barnard, P. L. Donaghay, and B. Rhoades (2006), Hyperspectral temper- 
ature and salt dependencies of absorption by water and heavy water in the 400-750 nm spectral range, Appl. Opt., 45, 5294-5309.

Sun, D. Y., Y. M. Li, Q. Wang, C. F. Le, C. C. Huang, and L. Z. Wang (2009), Parameterization of water component absorption in an inland eutrophic lake and its seasonal variability: A case study in Lake Taihu, Int. J. Remote Sens., 30, 3549-3571.

Svab, E., A. N. Tyler, T. Preston, M. Presing, and K. V. Balogh (2005), Characterizing the spectral reflectance of algae in lake waters with high suspended sediment concentrations, Int. J. Remote Sens., 26, 919-928.

Tarnocai, C. (2009), The impact of climate change on Canadian peatlands, Can. Water Resour. J., 34, 453-466.

Tassan, S., and G. M. Ferrari (1995), An alternative approach to absorption measurements of aquatic particles retained on filters, Limnol. Oceanogr. 40, 1358-1368.

Twardowski, M. S., J. M. Sullivan, P. L. Donaghay, and J. R. V. Zaneveld (1999), Microscale quantification of the absorption by dissolved and particulate material in coastal waters with an ac-9, J. Atmos. Oceanic Technol., 16, 691-707.

Tyler, A. N., E. Svab, T. Preston, M. Presing, and W. A. Kovacs (2006), Remote sensing of the water quality of shallow lakes: A mixture modelling approach to quantifying phytoplankton in water characterized by high-suspended sediment, Int. J. Remote Sens., 27, 1521-1537.

Tyler, J. E. (1964), Colour of the ocean, Nature, 202, 1262-1264

Vincent, W. F., J. J. Dodson, N. Bertrand, and J. J. Frenette (1996), Photosynthetic and bacterial production gradients in a larval fish nursery: The St Lawrence river transition zone, Mar. Ecol. Prog. Ser., 139 227-238.
Walter, K. M., S. A. Zimov, J. P. Chanton, D. Verbyla, and F. S. Chapin (2006), Methane bubbling from Siberian thaw lakes as a positive feedback to climate warming, Nature, 443, 71-75.

Watanabe, S., M. F. Knowlton, W. F. Vincent, and J. R. Jones (2009), Variability in the optical properties of colored dissolved organic matter in Missouri reservoirs, Verh. Int. Verein. Limnol., 30, 1117-1120.

Zaneveld, J. R. V., J. C. Kitchen, and C. M. Moore (1994), The scattering error correction of reflecting-tube absorption meters, Proc. SPIE Ocean Opt. XII, 2258, 44-55.

Zepp, R. G., G. C. Shank, E. Stabenau, K. W. Patterson, M. Cyterski, W. Fisher, E. Bartels, and S. L. Anderson (2008), Spatial and temporal variability of solar ultraviolet exposure of coral assemblages in the Florida Keys: Importance of colored dissolved organic matter, Limnol. Oceanogr., 53, 1909-1922.

Zhang, Y. L., L. Q. Feng, J. S. Li, L. C. Luo, Y. Yin, M. L. Liu, and Y. L. Li (2010), Seasonal-spatial variation and remote sensing of phytoplankton absorption in Lake Taihu, a large eutrophic and shallow lake in China, J. Plankton Res., 32, 1023-1037.

Zimov, S. A., E. A. G. Schuur, and F. S. Chapin (2006), Permafrost and the global carbon budget, Science, 312, 1612-1613.

K. Chokmani and I. Laurion, Centre Eau Terre Environnement, Institut national de la recherche scientifique, Québec City, QC G1V 4C7, Canada.

R. Pienitz, Département de Géographie, Université Laval, Québec City, QC G1V 0A6, Canada.

W. F. Vincent and S. Watanabe, Département de Biologie, Université Laval, Québec City, QC G1V 0A6, Canada. (shohei.watanabe.1@ulaval.ca) 